\title{
How Atoms of Polycrystalline Nb 20.6 Mo 21.7 Ta 15.6 W 21.1 V 21.0 refractory High-Entropy Alloys Rearrange during the Melting Process
}

Shin-Pon Ju ( $\sim$ jushin-pon@mail.nsysu.edu.tw )

National Sun Yat-sen University

Chen-Chun Li

National Sun Yat-sen University

\section{Research Article}

Keywords: refractory high entropy alloy, melting mechanism, polycrystalline, molecular dynamics, grain size, grain boundary, pre-melting temperature

Posted Date: October 27th, 2021

DOI: https://doi.org/10.21203/rs.3.rs-1010953/v1

License: (c) (i) This work is licensed under a Creative Commons Attribution 4.0 International License.

Read Full License 
How atoms of polycrystalline $\mathrm{Nb}_{20.6} \mathrm{Mo}_{21.7} \mathrm{Ta}_{15.6} \mathrm{~W}_{21.1} \mathrm{~V}_{21.0}$ refractory High-Entropy Alloys Rearrange during the Melting Process

\author{
Shin-Pon $\mathrm{Ju}^{1,2 *}$, and Chen-Chun $\mathrm{Li}^{1}$ \\ ${ }^{1}$ Department of Mechanical and Electro-Mechanical Engineering, National Sun Yat-sen \\ University, Kaohsiung 804, Taiwan \\ ${ }^{2}$ Department of Medicinal and Applied Chemistry, Kaohsiung Medical University, \\ Kaohsiung 807, Taiwan
}

*Corresponding author: jushin-pon@mail.nsysu.edu.tw (S.P. Ju) 


\begin{abstract}
The melting mechanism of single crystal and polycrystalline $\mathrm{Nb}_{20.6} \mathrm{Mo}_{21.7} \mathrm{Ta}_{15.6} \mathrm{~W}_{21.1} \mathrm{~V}_{21.0}$ RHEAs was investigated by the molecular dynamics (MD) simulation using the $2 \mathrm{NN}$ MEAM potential. For the single crystal RHEA, the density profile displays an abrupt drop from 11.25 to $11.00 \mathrm{~g} / \mathrm{cm}^{3}$ at temperatures from 2910 to $2940 \mathrm{~K}$, indicating all atoms begin significant local structural rearrangement. For polycrystalline RHEAs, a two-stage melting process is found. In the first melting stage, the melting of the grain boundary (GB) regions firstly occurs at the pre-melting temperature, which is relatively lower than the corresponding system-melting point. At the pre-melting temperature, most GB atoms have enough kinetic energies to leave their equilibrium positions, and then gradually induce the rearrangement of grain atoms close to GB. In the second melting stage at the melting point, most grain atoms have enough kinetic energies to rearrange, resulting in the chemical short-ranged order (CSRO) changes of all pairs.
\end{abstract}

Keywords: refractory high entropy alloy, melting mechanism, polycrystalline, molecular dynamics, grain size, grain boundary, pre-melting temperature 


\section{Introduction}

Materials used in the extreme working environments such as high temperatures or pressures are in an urgent need for industrial application. For example, to improve the efficiency of gas turbine engines in the aerospace industry, increasing engine operating temperature is one of the most effective ways [1]. However, the most commonly used hightemperature structural material, nickel-based superalloy, has its own melting point of about $1300{ }^{\circ} \mathrm{C}$, which limits the maximum operating temperature. Thus, it is very important that the material has a high enough melting point [2]. High entropy alloys (HEAs), also known as multi-principal-element alloys (MPEAs), are composed of major element types more than four [3]. Within HEAs, all compositional elements are arranged in the most uniformly distribution, leading to excellent material properties including high hardness [4], high strength and ductility combination [5, 6], good fatigue resistance [7], high temperature microstructure and mechanical stability [8], outstanding electromagnetic properties [9], excellent wear resistance [10], corrosion resistance [11], and oxidation resistance [12].

Among all HEAs, the refractory high entropy alloys (RHEAs) generally have one or more compositional refractory elements such as $\mathrm{W}, \mathrm{Mo}, \mathrm{Ta}, \mathrm{Nb}, \mathrm{Zr}$, and $\mathrm{Re}$ [13]. Accordingly, RHEAs display excellent high temperature resistance, high melting point $\left(>2000{ }^{\circ} \mathrm{C}\right.$ ), and higher high temperature strength, which has wide potential for applications in high temperature equipment. For examples, in 2010, the first RHEA, NbMoTaW RHEA, was fabricated by Senkov [14]. The yield strength of NbMoTaW RHEA at $1600{ }^{\circ} \mathrm{C}$ is $405 \mathrm{MPa}$, and the working temperature limit of $1600{ }^{\circ} \mathrm{C}$ is much higher than that of nickel-based high temperature alloys about $1300{ }^{\circ} \mathrm{C}$. The poor phase stability and low plasticity at high and medium temperatures are two bottlenecks to restrict the application of HEAs at high temperatures. Thus, In Nie's study [1], the HfMoScTaZr 
RHEAs were prepared by vacuum arc melting equipment. By adding Sc element, the density of the alloy becomes lower, and the strength and plasticity of HfMoScTaZr RHEAs were significantly improved. The yield strengths of HfMoScTaZr RHEAs at room temperature, $800{ }^{\circ} \mathrm{C}, 1000^{\circ} \mathrm{C}$ and $1200{ }^{\circ} \mathrm{C}$ are $1778,1118,963$ and $498 \mathrm{MPa}$, respectively. At $1200^{\circ} \mathrm{C}$, the yield strength of HfMoScTaZr RHEA is about 4.3 and 6 times higher than those of the traditional classic superalloys, Inconel 718 and CMSX-4. Besides the compositional element types and their related fractions, the material properties of HEAs or alloys are significantly affected by the extent of crystallinity. For examples, In Lin's study [15], the melt-ball milling-hot pressing process was adopted to fabricate the $\mathrm{Cu}_{3-\mathrm{x}} \mathrm{Ni}_{\mathrm{x}} \mathrm{SbSe}_{4}$ $(\mathrm{x}=0 \sim 0.03)$ alloys with different average grain sizes. The influences of average grain size on the microstructure and thermoelectric properties of $\mathrm{Cu}_{3-\mathrm{x}} \mathrm{Ni}_{\mathrm{x}} \mathrm{SbSe}_{4}$ were observed. Because of the grain refinement and Se defect increase, the lattice thermal conductivity decreases from $3.3 \mathrm{Wm}^{-1} \mathrm{~K}^{-1}$ to $2.4 \mathrm{Wm}^{-1} \mathrm{~K}^{-1}$ at room temperature when the fraction $\mathrm{Ni}$ fraction decreases from $x=0.03$ to 0 . In Sun's study [16], they experimental results indicate when the grain size of CoCrFeMnNi HEA decreases from $105 \mu \mathrm{m}$ to $650 \mathrm{~nm}$ at $293 \mathrm{~K}$, the yield strength increased from $225 \mathrm{MPa}$ to $798 \mathrm{MPa}$ with an increase of $254.7 \%$. At the same time, the ultimate tensile strength increases from $798 \mathrm{MPa}$ to $887 \mathrm{MPa}$ with an increase of $11.2 \%$.

For new RHEA development, it is essential to understand the thermal behavior of single crystal and polycrystalline RHEAs from the atomic scale. Using the empirical approach, it is relatively difficult to directly observe the atomic arrangement and diffusion at high temperatures. Consequently, the molecular simulation method has played an important role to investigate the atomic behaviors at high temperatures or during the 
melting process. For examples, in Rahman's MD simulation results [17], they found the steady-state creeping rate of $\mathrm{Cu} 0.5 \mathrm{Ni} 0.5$ alloy speeds up dramatically under the elevated stress and temperature as well as the decreasing grain size. The lattice and grain boundary

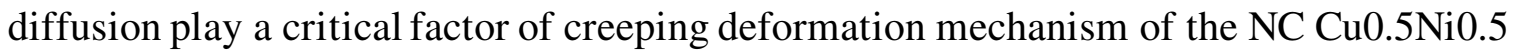
alloy. Giang studied the melting stages of $2 \mathrm{D}$ confined germanene in both perfect crystalline and polycrystalline states by MD simulation [18]. The temperatures from solid to liquid phase transition are about $1670 \mathrm{~K}$ and $1540 \mathrm{~K}$ for the crystalline and polycrystalline models, respectively. In Noori's study [19], the MD simulation was utilized to realize the effect of grain size on the melting temperature of $\mathrm{Al}$ nanocrystals. Their results show that the melting temperature becomes lower when the grain size is smaller. The pre-melting and melting at grain boundary regions does not take place instantly, and the melting of the polycrystalline $\mathrm{Al}$ occurs within a certain temperature range, rather than at a specific temperature.

The systematic investigation on how atoms rearrange for a single crystal and polycrystalline RHEAs during the heating process is still lacking. In order to explore the melting mechanism, the single crystal $\mathrm{Nb}_{20.6} \mathrm{Mo}_{21.7} \mathrm{Ta}_{15.6} \mathrm{~W}_{21.1} \mathrm{~V}_{21.0}$ RHEA and polycrystalline $\mathrm{Nb}_{20.6} \mathrm{Mo}_{21.7} \mathrm{Ta}_{15.6} \mathrm{~W}_{21.1} \mathrm{~V}_{21.0}$ RHEAs with the average grain sizes from 5.2 to $25.3 \mathrm{~nm}$ were used for the MD heating simulation from 300 to $3600 \mathrm{~K}$. The secondnearest neighbor modified embedded-atom method (2NN MEAM) potential was used to model the interaction among $\mathrm{Nb}, \mathrm{Mo}, \mathrm{Ta}, \mathrm{W}$, and $\mathrm{V}$ elements. The system enthalpy and square displacement at different temperatures of the heating process were used to determine the melting points of $\mathrm{Nb}_{20.6} \mathrm{Mo}_{21.7} \mathrm{Ta}_{15.6} \mathrm{~W}_{21.1} \mathrm{~V}_{21.0}$ RHEAs. The dynamical behaviors of different elements at grain boundaries and within grains were also investigated, 
and variations of affinity between any two element type pairs were investigated by the chemical short-ranged order (CSRO) during the heating process.

\section{Simulation model}

The second-nearest neighbor modified embedded atomic method (2NN MEAM) was used to describe the interactions among $\mathrm{Nb}, \mathrm{Mo}, \mathrm{T}, \mathrm{W}$, and $\mathrm{V}$ atoms. Table 1 lists the parameters of all single elements [20], and Tables 2 and 3 show all cross-element and ternary-element parameters of 2NN MEAM potential, parametrized by the reference data prepared by the density functional theory (DFT) calculation. The detailed parametrization process can be seen in the supplementary file of our previous study [21]. The ATOMSK package [22]was adopted to build the structures of polycrystalline $\mathrm{Nb}_{20.6} \mathrm{Mo}_{21.7} \mathrm{Ta}_{15.6} \mathrm{~W}_{21.1} \mathrm{~V}_{21.0}$ RHEAs with the average grain sizes of 25.3, 20.1, 15.6, 10.0, and $5.2 \mathrm{~nm}$. Figure 1 shows the polycrystalline $\mathrm{Nb}_{20.6} \mathrm{Mo}_{21.7} \mathrm{Ta}_{15.6} \mathrm{~W}_{21.1} \mathrm{~V}_{21.0}$ RHEA with the average grain size of $5.2 \mathrm{~nm}$. The system size is about 40.7, 40.7, and $40.7 \mathrm{~nm}$ in the $\mathrm{x}^{-}, \mathrm{y}-$, and $\mathrm{z}-$ dimensions, respectively. The atoms in Figs. 1(a)-(c) are colored according to the element type, grain and grain boundary atoms identified by the common neighbor analysis (CAN), and the grain identity number, respectively. Table 4 summarize the grain number and total atom number of the $\mathrm{Nb}_{20.6} \mathrm{Mo}_{21.7} \mathrm{Ta}_{15.6} \mathrm{~W}_{21.1} \mathrm{~V}_{21.0}$ RHEAs with average grain sizes from 5.2 to $31.9 \mathrm{~nm}$. The total atom number is about 4,113,600, and the atom numbers of different cases are slightly different. The single crystal $\mathrm{Nb}_{20.6} \mathrm{Mo}_{21.7} \mathrm{Ta}_{15.6} \mathrm{~W}_{21.1} \mathrm{~V}_{21.0}$ RHEA with 1,024,000 atoms is also listed in Table 4.

The maximum entropy (MaxEnt) theory [23] implemented by Monte Carlo (MC) method was used to have each compositional element undergo the most uniform 
distribution within all $\mathrm{Nb}_{20.6} \mathrm{Mo}_{21.7} \mathrm{Ta}_{15.6} \mathrm{~W}_{21.1} \mathrm{~V}_{21.0}$ RHEAs, resulting in the maximum configurational entropy state. The element type of each nearest neighbor atom of a reference atom is not the same as the element type of the reference atom.

Thermal behaviors of single crystal and polycrystalline $\mathrm{Nb}_{20.6} \mathrm{Mo}_{21.7} \mathrm{Ta}_{15.6} \mathrm{~W}_{21.1} \mathrm{~V}_{21.0}$ RHEAs were investigated by the MD temperature elevation process from 300 to $3600 \mathrm{~K}$. The heating process was processed in the increasing temperature by $10 \mathrm{~K}$ increment, and each increment was accompanied by a relaxation process in $10 \mathrm{ps}$ before the subsequent temperature increases. For maintaining the constant temperature under the free stress during the temperature elevation process, the TtN method was utilized [24]. This method combines the Parrinello-Rahman variable shape size ensemble with the Nosé-Hoover thermostat. For the heating simulation, the periodic boundary conditions (PBCs) were used in all dimensions. Large-scale atomic/molecular massively parallel simulator (LAMMPS) was utilized to perform all MD simulations, which was developed by Plimpton et al. [25]. The OVITO package [26] was used to do all visualization and post process of all simulation results.

\section{Results and Discussion}

Figure 2 shows the variations of GB atom fractions and atomic binding energies of $\mathrm{GB}$, grain, and system for $\mathrm{Nb}_{20.6} \mathrm{Mo}_{21.7} \mathrm{Ta}_{15.6} \mathrm{~W}_{21.1} \mathrm{~V}_{21.0}$ RHEAs with the average grain size from 5.2 to $25.3 \mathrm{~nm}$. It can be seen from Fig. 2 that the GB atom fraction decreases parabolically from $26.8 \%$ to $6.2 \%$ when the average grain size increases from 5.2 to 25.3 nm. In Fig. 1, according to the CNA results, atoms within the GB and grain are arranged in the undefined type and the BCC type, respectively. When the average grain size becomes 
smaller, the surface area to volume ratio of grains becomes higher. Accordingly, the fraction of GB atoms surrounding grains significantly increases, resulting in the increase of atoms at the GB/grain interface. Atoms at GB/grain interface possess higher local stresses and higher binding energy, so the atomic binding energy of GB, grain, and system decrease parabolically when the grain size increases from 5.2 to $25.3 \mathrm{~nm}$ as illustrated in Fig. 2. Because melting behaviors of $\mathrm{Nb}_{20.6} \mathrm{Mo}_{21.7} \mathrm{Ta}_{15.6} \mathrm{~W}_{21.1} \mathrm{~V}_{21.0}$ RHEAs with the average grain sizes from 5.2 to $25.3 \mathrm{~nm}$ are basically similar, only simulation results for the grain sizes of 25.3 and $5.2 \mathrm{~nm}$ were discussed. For comparison, the melting process of single crystal $\mathrm{Nb}_{20.6} \mathrm{Mo}_{21.7} \mathrm{Ta}_{15.6} \mathrm{~W}_{21.1} \mathrm{~V}_{21.0}$ RHEA was also investigated.

The Warren-Cowley chemical short-range-order (CSRO) analysis [27] for $\mathrm{Nb}_{20.6} \mathrm{Mo}_{21.7} \mathrm{Ta}_{15.6} \mathrm{~W}_{21.1} \mathrm{~V}_{21.0}$ RHEAs was used to quantify the attraction and repulsion between different elemental pairs and monitor the local structural rearrangement during the heating process. The chemical affinities of a referenced atom with its first neighbor atoms are evaluated by the CSRO parameter. The definition of this parameter is shown in the following equation:

$$
\alpha_{i j}=1-\frac{N_{i j}}{c_{j} N_{i}}
$$

where $\alpha_{i j}$ is the CSRO parameter of the $\mathrm{i}$-type referenced atom relative to j-type atom, $N_{i j}$ is the partial coordination number $(\mathrm{CN})$ for the $\mathrm{i}$-type referenced atom relative to $\mathrm{j}$-type atom obtained from the predicted structure, and $c_{j}$ and $N_{i}$ are the fractions of $\mathrm{j}$-type atom within the alloy and the average $\mathrm{CN}$ of i-type atoms, respectively. The value of $c_{j}$ by $N_{i}$ is an ideal partial $\mathrm{CN}$ for the referenced i-type atom relative to the first neighbor $\mathrm{j}$-type atom, and this value completely depends on the respective atomic composition fraction of $\mathrm{Nb}_{20.6} \mathrm{Mo}_{21.7} \mathrm{Ta}_{15.6} \mathrm{~W}_{21.1} \mathrm{~V}_{21.0}$ RHEA. The second term of Eq. (1) is the ratio of actual $\mathrm{CN}$ 
$\left(\mathrm{N}_{\mathrm{ij}}\right)$ to ideal $\mathrm{CN}\left(c_{j} N_{i}\right)$ for the i-type reference atom to its first neighbor $\mathrm{j}$-type atom. If this ratio is larger than 1 , it means the affinity of $\mathrm{j}$-type atom to $\mathrm{i}$-type atom in the predicted structure is higher than that in the ideal structure. On the other hand, if this ratio is lower than 1 , the affinity of $j$-type atom to $i$-type atom in the predicted structure is lower than that in the ideal structure. If the ratio is close to 1 , it infers the affinity of $\mathrm{j}$-type atom to $\mathrm{i}$-type atom in the predicted structure is close to that in the ideal structure. Consequently, the positive and negative values of CSRO indicate the lower and higher affinity of the element type pair, compared with their ideal affinity.

Figure 3 shows the CSRO distributions of all element type pairs for single crystal, grain sizes of 5.2 and $25.3 \mathrm{~nm}$ at $300 \mathrm{~K}$. All atoms within these three structures are arranged according to the MaxEnt theory, and the distance of the minimum between the first and second peaks of the radial distribution function (RDF) was used to determine CSRO values. In Fig. 3, CSRO values of pairs with the same element type are larger than 0.8 , indicating all element types of $\mathrm{Nb}_{20.6} \mathrm{Mo}_{21.7} \mathrm{Ta}_{15.6} \mathrm{~W}_{21.1} \mathrm{~V}_{21.0}$ RHEAs are arranged in the most uniform distribution. For pairs with different element types, all CSRO values are smaller than -0.1, indicating the affinity of all pairs with different element types is much higher than those with the same element types.

Figures 4(a)-(c) show the variations of density and enthalpy for single crystal, 25.3 $\mathrm{nm}$, and $5.2 \mathrm{~nm}$ during the heating process. Because the enthalpies (densities) increase (decrease) linearly with the increasing temperature from $300 \mathrm{~K}$ to specific temperatures for all cases, the lowest temperatures of the horizontal axes in Figs. 4(b) and 4(c) start from higher values for clearly showing the variations of density and enthalpy near the melting points. For the single crystal, the enthalpy increases linearly with the increasing 
temperature from 300 to $2910 \mathrm{~K}$ and then shows an abrupt increase from 2910 to $2940 \mathrm{~K}$, within which the local structure of single crystal $\mathrm{Nb}_{20.6} \mathrm{Mo}_{21.7} \mathrm{Ta}_{15.6} \mathrm{~W}_{21.1} \mathrm{~V}_{21.0}$ RHEA undergoes significantly rearrangement. Consequently, the melting temperature of single crystal $\mathrm{Nb}_{20.6} \mathrm{Mo}_{21.7} \mathrm{Ta}_{15.6} \mathrm{~W}_{21.1} \mathrm{~V}_{21.0}$ RHEA is $2940 \mathrm{~K}$, which is very close to the experimental value about 2946 K [28]. From 2940 to $3110 \mathrm{~K}$, the enthalpy decreases parabolically, and then increases linearly with the increasing temperature when the temperature continuously increases from 3110 K. In Fig. 3 for the single crystal, the CSRO values of pairs with the same element type indicate the lowest affinity for atoms to the same element types before the melting point. When the system temperature is higher than the melting point of $2940 \mathrm{~K}$, the atoms have enough kinetic energies to leave their equilibrium positions, and the elements possessing higher binding energies begin to aggregate together, resulting in the decrease of enthalpy from 2940 to $3110 \mathrm{~K}$. For the density profile, it decreases linearly with the increasing temperature from 300 to $2910 \mathrm{~K}$, and then, from 2910 to $2940 \mathrm{~K}$, the density displays an abrupt drop from 11.25 to 11.00 $\mathrm{g} / \mathrm{cm}^{3}$, indicating the system undergoes the significant local structural rearrangement. In Figs. 4(b) and 4(c), enthalpy profiles of $25.3 \mathrm{~nm}$ and $5.2 \mathrm{~nm}$ increase linearly with the increasing temperature from 2100 to $2900 \mathrm{~K}$ and from 1500 to $2540 \mathrm{~K}$, respectively. When temperatures continuously increase from 2900 to $3100 \mathrm{~K}$ for $25.3 \mathrm{~nm}$ and from 2540 to $2700 \mathrm{~K}$ for $5.2 \mathrm{~nm}$, enthalpies are almost unchanged. Within these temperature ranges, local structures undergo significantly rearrange. For the density profiles, the discontinuities at 2500 and $3100 \mathrm{~K}$ for $25.3 \mathrm{~nm}$ and the discontinuities at 2120 and $2860 \mathrm{~K}$ for $5.2 \mathrm{~nm}$ infer the local structural rearrangement smoothly proceeds during a wider temperature ranges, compared with the density drop within a narrow temperature range (2910-2940 K) 
for the single crystal. The temperatures of $2900 \mathrm{~K}$ and $2540 \mathrm{~K}$ are regarded as the melting points of $25.3 \mathrm{~nm}$ and $5.2 \mathrm{~nm}$.

Figure 5 shows the profile of the melting point for polycrystalline $\mathrm{Nb}_{20.6} \mathrm{Mo}_{21.7} \mathrm{Ta}_{15.6} \mathrm{~W}_{21.1} \mathrm{~V}_{21.0}$ RHEAs with the average grain sizes from 5.2 to $25.3 \mathrm{~nm}$. The melting points were temperatures at which the slope of the enthalpy profile begins to change. The horizontal dashed line at $2940 \mathrm{~K}$ stands for the melting point of the single crystal $\mathrm{Nb}_{20.6} \mathrm{Mo}_{21.7} \mathrm{Ta}_{15.6} \mathrm{~W}_{21.1} \mathrm{~V}_{21.0}$ RHEA. It is obvious that the melting point and the grain size display the relationship of logarithmic growth. The increase in the melting point by increasing the grain size is more significant for smaller grains. Consequently, an empirical equation shown below can be used to evaluate the melting point of polycrystalline $\mathrm{Nb}_{20.6} \mathrm{Mo}_{21.7} \mathrm{Ta}_{15.6} \mathrm{~W}_{21.1} \mathrm{~V}_{21.0}$ RHEAs with much larger grain sizes:

$$
T_{m}(d)=T_{0} \exp \left(a / d^{n}\right)
$$

where $T_{m}(d), T_{0}$, and $d$ are the melting point of the case with the average grain size of $d$, the melting point of single crystal, and the average grain size, respectively. Two parameters, $\mathrm{a}$ and $\mathrm{n}$ (the power of $\mathrm{d}$ ) are determined by the parametrization process using the available data from the MD simulation. The fitted values of a and $\mathrm{n}$ are -1.2 and 1.27, and the profile of the curve fitting is also shown in Fig. 5, demonstrating the melting points of $\mathrm{Nb}_{20.6} \mathrm{Mo}_{21.7} \mathrm{Ta}_{15.6} \mathrm{~W}_{21.1} \mathrm{~V}_{21.0}$ RHEAs with much larger grain sizes gradually approach the value of the single crystal.

The square displacement $(\mathrm{SD})$ profile during the temperature elevation was used to observe the melting behaviors of single crystal and cases with the grain sizes of 25.3 and $5.2 \mathrm{~nm}$ for $\mathrm{Nb}_{20.6} \mathrm{Mo}_{21.7} \mathrm{Ta}_{15.6} \mathrm{~W}_{21.1} \mathrm{~V}_{21.0}$ RHEAs. The definition of $\mathrm{SD}$ at time $\mathrm{t}$ is shown in Eq. (3): 


$$
\mathrm{SD}(\mathrm{t})=\frac{\sum_{i}^{N}\left[r_{i}(t)-r_{i}(0)\right]^{2}}{N}
$$

where $r_{i}(0)$ is the position of the $i$-th atom at time $0, r_{i}(t)$ represents the position of the $i$ th atom at time $t$, and $\mathrm{N}$ is the total atom number in the system. The variation of $\mathrm{SD}$ is a sensitive parameter to investigate the extent of average atomic movement respect to a reference structure. Figure 6 illustrates the variations of SD values of all element types and average enthalpy during the heating process for the single crystal $\mathrm{Nb}_{20.6} \mathrm{Mo}_{21.7} \mathrm{Ta}_{15.6} \mathrm{~W}_{21.1} \mathrm{~V}_{21.0}$ RHEA. The melting point is also indicated by the dashed line. When temperatures exceed the melting point at $2940 \mathrm{~K}$, the SD profile of each element type displays an abrupt increase. The insert of Fig. 6 shows all SD profiles at temperatures lower than the melting point, and these profiles are closely matched, indicating the collective dynamical behavior of atoms within the RHEA. SD values of all element types increase with the increasing temperature when atoms undergo thermal vibration at temperatures lower than the melting point of $2940 \mathrm{~K}$. At temperatures higher than or equal to the melting point, atoms have enough kinetic energies to leave their lattice sites, so SD values increase dramatically. The distinct rise of SD profiles at $2940 \mathrm{~K}$ also confirms the significant local structural arrangement at the melting point of single crystal $\mathrm{Nb}_{20.6} \mathrm{Mo}_{21.7} \mathrm{Ta}_{15.6} \mathrm{~W}_{21.1} \mathrm{~V}_{21.0}$ RHEA.

In Fig 3 for the single crystal, one can see the CSRO values of pairs with the same element type are positive and larger than 0.95 , while the CSRO values of pairs with different element types are negative. It is very complicated to investigate the CSRO values of all pairs during the heating process, so the average values of CSRO square for pairs with the same element type and with different element types were used to monitor the change 
of chemical short-ranged order during the heating process. For the single crystal $\mathrm{Nb}_{20.6} \mathrm{Mo}_{21.7} \mathrm{Ta}_{15.6} \mathrm{~W}_{21.1} \mathrm{~V}_{21.0}$ RHEA, the average value of CSRO square of the same element type shown in Fig. 7 displays linearly decrease with the increasing temperature from 300 to $2530 \mathrm{~K}$, and then decreases parabolically with the rising temperature from 2530 to $2920 \mathrm{~K}$. The extent of lattice distortion and the increase in thermal vibration amplitude become more significant when the system temperature of single crystal $\mathrm{Nb}_{20.6} \mathrm{Mo}_{21.7} \mathrm{Ta}_{15.6} \mathrm{~W}_{21.1} \mathrm{~V}_{21.0}$ RHEA continuously increases. Consequently, the distance between the first and second RDF peaks becomes closer when the temperature continuously increases, which can be seen in the inserts of RDF profiles at temperatures from 310 to $1500 \mathrm{~K}$. At $1500 \mathrm{~K}$, the first and second RDF peaks have been merged into a single peak. When the temperature continuously increases from 1500 to $2530 \mathrm{~K}$, the first RDF peak becomes wider. It also leads to the linear decrease in the average value of CSRO square of the same element type. From 2530 to $2920 \mathrm{~K}$, the value of the first RDF minimum increases with the increasing temperature. Some atoms have higher opportunity to contact with their second and third neighbor atoms with the same element type, leading to the significant decrease in the average CSRO square of the same element type from 2530 to $2920 \mathrm{~K}$. At $2920 \mathrm{~K}$, the average CSRO square of the same element type reaches its minimum, indicating the chemical short-ranged order of the same element types undergoes a critical change from less affinity to no preference. When the temperature increases from the melting point of $2940 \mathrm{~K}$, the average CSRO square value of the same element type significantly rises. For different element types, the average value of CSRO square is relatively smaller and remains a constant at temperatures below the melting point of 2940 K. At temperatures above the melting point, the average value of CSRO square of different 
element pairs also displays an abrupt increase, which indicates the CSRO of different element types also undergoes a critical change at temperatures above $2940 \mathrm{~K}$.

Figure 8(a) demonstrates the CSRO distributions of all element type pairs at four characteristic temperatures, 2530, 2920 (minimum of CSRO square), 2940 (melting point), and $3110 \mathrm{~K}$. At $2530 \mathrm{~K}$, the CSRO values of the same element type pairs are about 0.75 , which are smaller than the corresponding values about 0.98 shown in Fig. 3. For the pairs of different element types, the CSRO values are very similar to those shown in Fig. 3. At 2920 K, it can be seen from Fig. 8(a) that the absolute values of all CSRO pairs become very small, and the CSRO values of the same element pairs are very close to 0 . At the melting point of $2940 \mathrm{~K}$ and $3110 \mathrm{~K}$, most CSRO values show considerable changes as compared to those at $2530 \mathrm{~K}$ and those of $300 \mathrm{~K}$ shown in Fig. 3. For investigating the CSRO change between $300 \mathrm{~K}$ and $3110 \mathrm{~K}$, Fig. 8(b) shows the differences of all CSRO pairs between $300 \mathrm{~K}$ and $3110 \mathrm{~K}$. The values in Fig. 8(b) are the CSRO values at $3110 \mathrm{~K}$ subtract the corresponding CSRO values at $300 \mathrm{~K}$. Consequently, the positive value of CSRO difference stands for the chemical affinity of an element type pair becomes weaker, whereas the negative value indicates the affinity of an element type pair becomes stronger. In Fig. 8(b), one can see the CSRO differences of the same element type pairs are negative, indicating the affinity of the same element undergoes significant change at temperatures higher than the melting point. Figure 9 shows the atom distributions of $\mathrm{Nb}, \mathrm{Mo}, \mathrm{W}$, Ta, and $\mathrm{V}$ within the single crystal $\mathrm{Nb}_{20.6} \mathrm{Mo}_{21.7} \mathrm{Ta}_{15.6} \mathrm{~W}_{21.1} \mathrm{~V}_{21.0}$ RHEA at $3110 \mathrm{~K}$. One can see the aggregation of $\mathrm{Nb}, \mathrm{Mo}, \mathrm{W}, \mathrm{Ta}$, and $\mathrm{V}$ is very obvious. For different element type pairs as shown in Fig. 8(b), most of their CSRO differences are positive, indicating these element pairs become less affinity after the structural rearrangement after the melting. 
Figures 10(a) and 10(b) show the displacement vectors of all atoms at the melting temperature of $2940 \mathrm{~K}$ and $3110 \mathrm{~K}$, respectively. The structure at $300 \mathrm{~K}$ is used as the reference structure to determine the atomic displacement vectors using OVITO. At 2940 $\mathrm{K}$, one can see the displacement vector lengths of most atoms are longer than those in thermal vibration (marked in blue), indicating these atoms are far away from their equilibrium positions. At $3110 \mathrm{~K}$, the displacement vector lengths of all atoms become much longer and the local structure is under significant change.

The SD and binding energy profiles of atoms within the grain and GB during the temperature elevation are shown in Fig. 11(a) and 11(b) for the case with the grain size of $25.3 \mathrm{~nm}$, respectively. For the profiles of binding energy, both the values of grain and GB increase linearly with the increasing temperature from 2100 to $2800 \mathrm{~K}$ and from 2100 to $2670 \mathrm{~K}$. Then binding energies of grain and GB display parabolic increase from 2800 to $2920 \mathrm{~K}$ and from 2670 to $2820 \mathrm{~K}$, respectively. At temperatures higher than $2800 \mathrm{~K}$ for grain and $2670 \mathrm{~K}$ for GB, SD values begin to rise dramatically, indicating the local structural rearrangement occurs at these temperatures. It can see the temperature for GB structural rearrangement is relatively lower than that of grain. Consequently, at $2820 \mathrm{~K}$, most GB atoms have enough kinetic energies to leave their equilibrium positions, and then these GB atoms gradually induce the rearrangement of grain atoms close to GB. Consequently, the temperature of $2820 \mathrm{~K}$ can be regarded as the pre-melting temperature, at which the melting of GB has been completed. When the temperatures continuously increase from $2920 \mathrm{~K}$ to $3100 \mathrm{~K}$ for grain and from $2820 \mathrm{~K}$ to $3100 \mathrm{~K}$ for GB, the binding energies decrease with the increasing temperature, and it indicates atoms of the same element types have a higher opportunity to contact each other. It should be noted the 
temperature, $2920 \mathrm{~K}$ (very close to the melting point obtained from enthalpy profile), is located at the binding energy peak of grain atoms, and it indicates most grain atoms have enough kinetic energies to rearrange. At temperature higher than $3100 \mathrm{~K}$, the binding energies of grain and GB also illustrate linear increase with the increasing temperature.

The average CSRO square profiles of the case with the average grain size of $25.3 \mathrm{~nm}$ during the heating process were shown in Fig. 12. RDF profiles at different temperatures are also shown in the inserts. One can see the value of the first RDF minimum become larger when the temperature continuously increases, leading to the decrease in the average CSRO square value. The minimum of the average CSRO square is at $2780 \mathrm{~K}$ as indicated by (I), below which the average CSRO square value of different element pairs is almost constant. When the temperature continuously increases from $2780 \mathrm{~K}$ to the melting point of $2900 \mathrm{~K}$, both CSRO square profiles display linear increase with the increasing temperature. When the temperature increases from the melting point, these two CSRO square profiles begin the significant increase with the increasing temperature. The CSRO distributions for the $\mathrm{Nb}_{20.6} \mathrm{Mo}_{21.7} \mathrm{Ta}_{15.6} \mathrm{~W}_{21.1} \mathrm{~V}_{21.0}$ RHEA with the average grain size of 25.3 $\mathrm{nm}$ at 2780 (minimum of average CSRO square), 2820 (pre-melting temperature), 2900 (melting point), and 2920 (binding energy peak of grain atom) K are illustrated in Fig. 13. At the pre-melting temperature, $2820 \mathrm{~K}$, the $\mathrm{GB}$ atoms and some grain atoms close to $\mathrm{GB}$ have undergone significant local structural arrangement, leading to the CSRO changes of these atoms. The CSRO value variations of different element pairs at temperatures higher than the pre-melting temperature are very similar to those of single crystal $\mathrm{Nb}_{20.6} \mathrm{Mo}_{21.7} \mathrm{Ta}_{15.6} \mathrm{~W}_{21.1} \mathrm{~V}_{21.0}$ RHEA at temperatures higher than that with the minimum of average CSRO square as shown in Fig. 8(a). 
For investigating the melting processes of GB and grain of the $\mathrm{Nb}_{20.6} \mathrm{Mo}_{21.7} \mathrm{Ta}_{15.6} \mathrm{~W}_{21.1} \mathrm{~V}_{21.0}$ RHEA with the average grain size of $25.3 \mathrm{~nm}$, the atom displacement vectors of 2820 (the pre-melting temperature), 2920 (20 K higher than the melting point), and $3100 \mathrm{~K}$ shown in Figs. 14(a)-(c) were used. The atom positions of the structure at $300 \mathrm{~K}$ were used as the reference, and the vectors were colored according to the length of a vector. In Fig. 14(a), most GB atoms have larger displacement vector sizes (marked in red), and some grain atoms close to the GB atoms are also affected by the GB atoms, which possess larger displacement vector sizes (marked in green) as compared to those at the cores of grains (marked in blue). At $2920 \mathrm{~K}$ as shown in Fig. 14(b), more grain atoms have large displacement vectors and the melting occurs toward the cores of grains. At $3100 \mathrm{~K}$, the displacement vectors in Fig. 14(c) indicates all atoms within the $\mathrm{Nb}_{20.6} \mathrm{Mo}_{21.7} \mathrm{Ta}_{15.6} \mathrm{~W}_{21.1} \mathrm{~V}_{21.0}$ RHEA with the average grain size of $25.3 \mathrm{~nm}$ have left their equilibrium positions and the system is in the melting state.

The SD and binding energy profiles of grain and GB atoms during the temperature elevation process are shown in Fig. 15(a) and 15(b) for the case with the average grain size of $5.2 \mathrm{~nm}$, respectively. Variations of SD and binding energies with the increasing temperature are very similar to those of the case with the grain size of $25.3 \mathrm{~nm}$ as shown in Figs. 11(a) and 11(b). For the case with a smaller average grain size, the pre-melting temperature of $2460 \mathrm{~K}$ is lower than that of $25.3 \mathrm{~nm}$ about $2820 \mathrm{~K}$.

The average CSRO square profiles of the case with the average grain size of $5.2 \mathrm{~nm}$ during the heating process were shown in Fig. 16. RDF profiles at different temperatures are also shown in the inserts. The value of the first RDF minimum also becomes larger when the temperature continuously increases, leading to the decrease in the average CSRO 
square value. The minimum of the average CSRO square is at $2340 \mathrm{~K}$ as indicated by (I), below which the average CSRO square value of different element pairs is almost constant. When the temperature continuously increases from $2340 \mathrm{~K}$ to the pre-melting temperature of $2460 \mathrm{~K}$, both CSRO square profiles slightly increase with the increasing temperature. Within this temperature range, most GB atoms have enough kinetic energies to rearrange, while most grain atoms still conduct the thermal vibration at their equilibrium positions. From the pre-melting temperature of $2460 \mathrm{~K}$ to the melting temperature of $2540 \mathrm{~K}$, GB atoms leaving their equilibrium positions further affect grain atoms close to GB atoms to leave from their equilibrium positions. Consequently, these two CSRO square profiles increase significantly with the increasing temperature, revealing the short-ranged order of this RHEA undergoes considerable change. The CSRO distributions for the $\mathrm{Nb}_{20.6} \mathrm{Mo}_{21.7} \mathrm{Ta}_{15.6} \mathrm{~W}_{21.1} \mathrm{~V}_{21.0}$ RHEA with the average grain size of $5.2 \mathrm{~nm}$ at 2340 (minimum of CSRO square), 2460 (pre-melting temperature), and 2540 (melting point and the binding energy peak of grain atom) $\mathrm{K}$ are illustrated in Fig. 17. CSRO variations of different element pairs during the melting process are very similar to those shown in Fig. 13 for the case of $25.3 \mathrm{~nm}$.

The atom displacement vectors at $2460 \mathrm{~K}$ (pre-melting temperature), $2540 \mathrm{~K}$ (melting point and the binding energy peak of grain atom), and $2700 \mathrm{~K}$ are shown in Figs. 18(a)-(c). The structure at $2000 \mathrm{~K}$ was used as the reference for calculating the atomic displacement vectors. The atom positions of the structure at $300 \mathrm{~K}$ were used as the reference, and the vectors were colored according to the length of a vector. In Fig. 18(a), GB atoms and grain atoms close to GB have longer displacement vector sizes (marked in red and green), as compared with those at the cores of grains (marked in blue). At $2540 \mathrm{~K}$ as shown in Fig. 
18(b), more grain atoms have large displacement vector lengths and the melting occurs toward the cores of grains. At $2700 \mathrm{~K}$, the displacement vectors in Fig. 18(c) indicates all atoms within the $\mathrm{Nb}_{20.6} \mathrm{Mo}_{21.7} \mathrm{Ta}_{15.6} \mathrm{~W}_{21.1} \mathrm{~V}_{21.0}$ RHEA with the average grain size of $5.2 \mathrm{~nm}$ leave their equilibrium positions and the system is in the melting state.

\section{Conclusion}

This study employs the MD simulation using 2NN MEAM potential to investigate the melting mechanism and the CSRO change for the single crystal and polycrystalline $\mathrm{Nb}_{20.6} \mathrm{Mo}_{21.7} \mathrm{Ta}_{15.6} \mathrm{~W}_{21.1} \mathrm{~V}_{21.0}$ RHEAs with the average grain sizes of 5.2, 10.0, 15.6, 20.1, and $25.3 \mathrm{~nm}$. The MaxEnt theory was used to build the structures for all $\mathrm{Nb}_{20.6} \mathrm{Mo}_{21.7} \mathrm{Ta}_{15.6} \mathrm{~W}_{21.1} \mathrm{~V}_{21.0}$ RHEAs. For polycrystalline $\mathrm{Nb}_{20.6} \mathrm{Mo}_{21.7} \mathrm{Ta}_{15.6} \mathrm{~W}_{21.1} \mathrm{~V}_{21.0}$ RHEAs, the GB atom fraction increases parabolically from $6.2 \%$ to $26.8 \%$ when the average grain size decreases from 25.3 to $5.2 \mathrm{~nm}$. At $300 \mathrm{~K}$, CSRO values of the same element type pairs are larger than 0.8 , indicating that all element types are arranged in the most uniform distribution. For pairs of different element types, all CSRO values are smaller than -0.1 , indicating that the affinity of these pairs is much higher than those with the same element types. During the heating process, the density profile of single crystal $\mathrm{Nb}_{20.6} \mathrm{Mo}_{21.7} \mathrm{Ta}_{15.6} \mathrm{~W}_{21.1} \mathrm{~V}_{21.0}$ RHEA displays an abrupt drop from 11.25 to $11.00 \mathrm{~g} / \mathrm{cm}^{3}$ from 2910 to $2940 \mathrm{~K}$, within which the enthalpy reaches its maximum value. It indicates all atoms begin the significant local structural rearrangement at $2940 \mathrm{~K}$, implying the atoms of single crystal $\mathrm{Nb}_{20.6} \mathrm{Mo}_{21.7} \mathrm{Ta}_{15.6} \mathrm{~W}_{21.1} \mathrm{~V}_{21.0}$ RHEA have a collective behavior during the melting process. When the temperature increases from $2940 \mathrm{~K}$, the enthalpy first becomes lower until $3110 \mathrm{~K}$ and then displays linear increase with the increasing temperature from 
$3110 \mathrm{~K}$. When the system temperature is higher than the melting point of $2940 \mathrm{~K}$, atoms have enough kinetic energies to leave their equilibrium positions, and the elements possessing higher binding energies begin to aggregate, resulting in the decrease of enthalpy from 2940 to $3110 \mathrm{~K}$.

For the melting mechanism of polycrystalline $\mathrm{Nb}_{20.6} \mathrm{Mo}_{21.7} \mathrm{Ta}_{15.6} \mathrm{~W}_{21.1} \mathrm{~V}_{21.0}$ RHEAs, a two-stage melting process is proposed. The first melting stage is the melting of GB, and then the second melting stage is the melting of grains. In the first melting stage, the temperature for GB structural rearrangement is relatively lower than that of grain, and this temperature is the pre-melting temperature, at which most GB atoms have enough kinetic energies to leave their equilibrium positions, and then these GB atoms gradually induce the rearrangement of grain atoms close to GB. Pre-melting temperatures of grains of $25.3 \mathrm{~nm}$ and $5.2 \mathrm{~nm}$ are $2820 \mathrm{~K}$ and $2460 \mathrm{~K}$, inferring the pre-melting temperature significantly depends on the average grain size. In the second melting stage at the melting point, most grain atoms have enough kinetic energies to rearrange, resulting in the CSRO changes of all pairs.

According to the melting points obtained by the MD simulation, the melting point and the grain size of polycrystalline $\mathrm{Nb}_{20.6} \mathrm{Mo}_{21.7} \mathrm{Ta}_{15.6} \mathrm{~W}_{21.1} \mathrm{~V}_{21.0}$ RHEAs have the relationship of logarithmic growth. The melting point, $\mathrm{T}_{\mathrm{m}}(\mathrm{d})$, of the $\mathrm{Nb}_{20.6} \mathrm{Mo}_{21.7} \mathrm{Ta}_{15.6} \mathrm{~W}_{21.1} \mathrm{~V}_{21.0} \mathrm{RHEA}$ with the average grain size of $\mathrm{d} \mathrm{nm}$ can be determined by the following formula:

$$
T_{m}(d)=2940 \times \operatorname{Exp}\left(-1.2 / d^{1.27}\right)
$$

For the CSRO difference between $300 \mathrm{~K}$ and the melting point, the cases of single crystal and polycrystalline $\mathrm{Nb}_{20.6} \mathrm{Mo}_{21.7} \mathrm{Ta}_{15.6} \mathrm{~W}_{21.1} \mathrm{~V}_{21.0}$ RHEAs are very similar. CSRO differences of the same element type pairs are negative, indicating the affinity between the 
same element types undergoes significant change at temperatures higher than the melting point, resulting in the aggregation of $\mathrm{Nb}, \mathrm{Mo}, \mathrm{W}, \mathrm{Ta}$, and $\mathrm{V}$. For different element type pairs, most of their CSRO differences are positive, implying that these element type pairs become less affinity after the structural rearrangement at temperatures higher than the melting point.

\section{Acknowledgments}

The authors would like to thank the (1) Ministry of Science and Technology of Taiwan, under Grant No. 109-2221-E-110 -007 -MY3 (2) NSYSU-KMU JOINT RESEARCH PROJECT, (\#NSYSUKMU 110-P010). 


\section{Reference}

[1] X. W. Nie, M. D. Cai, and S. Cai, "Microstructure and mechanical properties of a novel refractory high entropy alloy HfMoScTaZr," International Journal of Refractory Metals and Hard Materials, vol. 98, p. 105568, 2021/08/01/2021, doi: https://doi.org/10.1016/j.ijrmhm.2021.105568.

[2] X. J. Gao et al., "Microstructure characteristics and mechanical properties of Hf0.5Mo0.5NbTiZr refractory high entropy alloy with $\mathrm{Cr}$ addition," International Journal of Refractory Metals and Hard Materials, vol. 95, p. 105405, 2021/02/01/ 2021, doi: https://doi.org/10.1016/j.ijrmhm.2020.105405.

[3] S. J. Sun, Y. Z. Tian, H. R. Lin, Z. J. Wang, and Z. F. Zhang, "Revisiting the role of prestrain history in the mechanical properties of ultrafine-grained CoCrFeMnNi high-entropy alloy," Materials Science and Engineering: A, vol. 801, p. 140398, 2021/01/13/ 2021, doi: https://doi.org/10.1016/j.msea.2020.140398.

[4] W. Huo et al., "Ultrahigh hardness and high electrical resistivity in nano-twinned, nanocrystalline high-entropy alloy films," Applied Surface Science, vol. 439, pp. 222-225, 2018/05/01/2018, doi: https://doi.org/10.1016/j.apsusc.2018.01.050.

[5] S. J. Sun et al., "Enhanced strength and ductility of bulk CoCrFeMnNi high entropy alloy having fully recrystallized ultrafine-grained structure," Materials \& Design, vol. 133, pp. 122-127, 2017/11/05/ 2017, doi: https://doi.org/10.1016/j.matdes.2017.07.054.

[6] Z. Li, K. G. Pradeep, Y. Deng, D. Raabe, and C. C. Tasan, "Metastable highentropy dual-phase alloys overcome the strength-ductility trade-off," Nature, vol. 534, no. 7606, pp. 227-230, 2016/06/01 2016, doi: 10.1038/nature17981.

[7] Z. Tang, T. Yuan, C.-W. Tsai, J.-W. Yeh, C. D. Lundin, and P. K. Liaw, "Fatigue behavior of a wrought $\mathrm{Al} 0.5 \mathrm{CoCrCuFeNi}$ two-phase high-entropy alloy," Acta Materialia, vol. 99, pp. 247-258, 2015/10/15/ 2015, doi: https://doi.org/10.1016/j.actamat.2015.07.004.

[8] X. Yang et al., "A novel, non-equiatomic NiCrWFeTi high-entropy alloy with exceptional phase stability," Materials Letters, vol. 263, p. 127202, 2020/03/15/ 2020, doi: https://doi.org/10.1016/j.matlet.2019.127202.

[9] Y. Zhang, T. Zuo, Y. Cheng, and P. K. Liaw, "High-entropy Alloys with High Saturation Magnetization, Electrical Resistivity, and Malleability," Scientific Reports, Article vol. 3, p. 1455, 03/15/online 2013, doi: 10.1038/srep01455

https://www.nature.com/articles/srep01455\#supplementary-information.

[10] R. B. Nair, H. S. Arora, S. Mukherjee, S. Singh, H. Singh, and H. S. Grewal, "Exceptionally high cavitation erosion and corrosion resistance of a high entropy alloy," Ultrasonics Sonochemistry, vol. 41, pp. 252-260, 2018/03/01/ 2018, doi: https://doi.org/10.1016/j.ultsonch.2017.09.044.

[11] S. Shuang, Z. Y. Ding, D. Chung, S. Q. Shi, and Y. Yang, "Corrosion resistant nanostructured eutectic high entropy alloy," Corrosion Science, vol. 164, p. 108315, 2020/03/01/ 2020, doi: https://doi.org/10.1016/j.corsci.2019.108315.

[12] B. Gorr, M. Azim, H. J. Christ, T. Mueller, D. Schliephake, and M. Heilmaier, "Phase equilibria, microstructure, and high temperature oxidation resistance of novel refractory high-entropy alloys," Journal of Alloys and Compounds, vol. 624, pp. 270-278, 2015/03/05/2015, doi: https://doi.org/10.1016/j.jallcom.2014.11.012. 
[13] D. B. Miracle and O. N. Senkov, "A critical review of high entropy alloys and related concepts," Acta Materialia, vol. 122, pp. 448-511, 2017/01/01/ 2017, doi: https://doi.org/10.1016/j.actamat.2016.08.081.

[14] O. N. Senkov, G. B. Wilks, D. B. Miracle, C. P. Chuang, and P. K. Liaw, "Refractory high-entropy alloys," Intermetallics, vol. 18, no. 9, pp. 1758-1765, 2010/09/01/ 2010, doi: https://doi.org/10.1016/j.intermet.2010.05.014.

[15] L. Bo et al., "Grain size and compositional gradient dependence of thermoelectric performance for Cu3-xNixSbSe4 materials," Results in Physics, vol. 26, p. 104337, 2021/07/01/ 2021, doi: https://doi.org/10.1016/j.rinp.2021.104337.

[16] S. J. Sun, Y. Z. Tian, X. H. An, H. R. Lin, J. W. Wang, and Z. F. Zhang, "Ultrahigh cryogenic strength and exceptional ductility in ultrafine-grained $\mathrm{CoCrFeMnNi}$ high-entropy alloy with fully recrystallized structure," Materials Today Nano, vol. 4, pp. 46-53, 2018/12/01/2018, doi: https://doi.org/10.1016/j.mtnano.2018.12.002.

[17] M. H. Rahman, E. H. Chowdhury, and S. Hong, "Nature of creep deformation in nanocrystalline cupronickel alloy: A Molecular Dynamics study," Results in Materials, vol. 10, p. 100191, 2021/06/01/ 2021, doi: https://doi.org/10.1016/j.rinma.2021.100191.

[18] N. Hoang Giang, V. Van Hoang, and T. Thi Thu Hanh, "Melting of twodimensional perfect crystalline and polycrystalline germanene," Physica E: Lowdimensional Systems and Nanostructures, vol. 119, p. 114021, 2020/05/01/ 2020, doi: https://doi.org/10.1016/j.physe.2020.114021.

[19] Z. Noori, M. Panjepour, and M. Ahmadian, "Study of the effect of grain size on melting temperature of Al nanocrystals by molecular dynamics simulation," Journal of Materials Research, vol. 30, no. 10, pp. 1648-1660, 2015, doi: 10.1557/jmr.2015.109.

[20] B.-J. Lee, M. I. Baskes, H. Kim, and Y. Koo Cho, "Second nearest-neighbor modified embedded atom method potentials for bcc transition metals," Physical Review B, vol. 64, no. 18, p. 184102, 10/15/ 2001, doi: 10.1103/PhysRevB.64.184102.

[21] S.-P. J. C.-C. Li, "Role of local FCC structure to the BCC polycrystalline NbMoTaWV Refractory High Entropy Alloy under Plastic Deformation."

[22] P. Hirel, "Atomsk: A tool for manipulating and converting atomic data files," Computer Physics Communications, vol. 197, pp. 212-219, 2015/12/01/ 2015, doi: https://doi.org/10.1016/j.cpc.2015.07.012.

[23] S. Wang, "Atomic Structure Modeling of Multi-Principal-Element Alloys by the Principle of Maximum Entropy," Entropy, vol. 15, no. 12, 2013, doi: 10.3390/e15125536.

[24] Y. Qi, T. Çağın, Y. Kimura, and W. A. Goddard, "Molecular-dynamics simulations of glass formation and crystallization in binary liquid metals: $\mathrm{Cu}-\mathrm{Ag}$ and $\mathrm{Cu}-\mathrm{Ni}$," Physical Review B, vol. 59, no. 5, pp. 3527-3533, 02/01/ 1999, doi: 10.1103/PhysRevB.59.3527.

[25] S. Plimpton, "Fast Parallel Algorithms for Short-Range Molecular Dynamics," Journal of Computational Physics, vol. 117, no. 1, pp. 1-19, 1995/03/01/ 1995, doi: https://doi.org/10.1006/jcph.1995.1039.

[26] A. Stukowski, "Visualization and analysis of atomistic simulation data with OVITO-the Open Visualization Tool," Modelling and Simulation in Materials 
Science and Engineering, vol. 18, no. 1, p. 015012, 2009/12/15 2009, doi: 10.1088/0965-0393/18/1/015012.

[27] R. N. Singh and F. Sommer, "Segregation and immiscibility in liquid binary alloys," Reports on Progress in Physics, vol. 60, no. 1, pp. 57-150, 1997/01/01 1997, doi: 10.1088/0034-4885/60/1/003.

[28] O. N. Senkov, G. B. Wilks, J. M. Scott, and D. B. Miracle, "Mechanical properties of Nb25Mo25Ta25W25 and V20Nb20Mo20Ta20W20 refractory high entropy alloys," Intermetallics, vol. 19, no. 5, pp. 698-706, 2011/05/01/ 2011, doi: https://doi.org/10.1016/j.intermet.2011.01.004.

Acknowledgements

The authors would like to thank the (1) Ministry of Science and Technology of Taiwan, under Grant No. 109-2221-E-110 -007 -MY3 (2) NSYSU-KMU JOINT RESEARCH PROJECT, (\#NSYSUKMU 110-P010). 


\section{Figures}
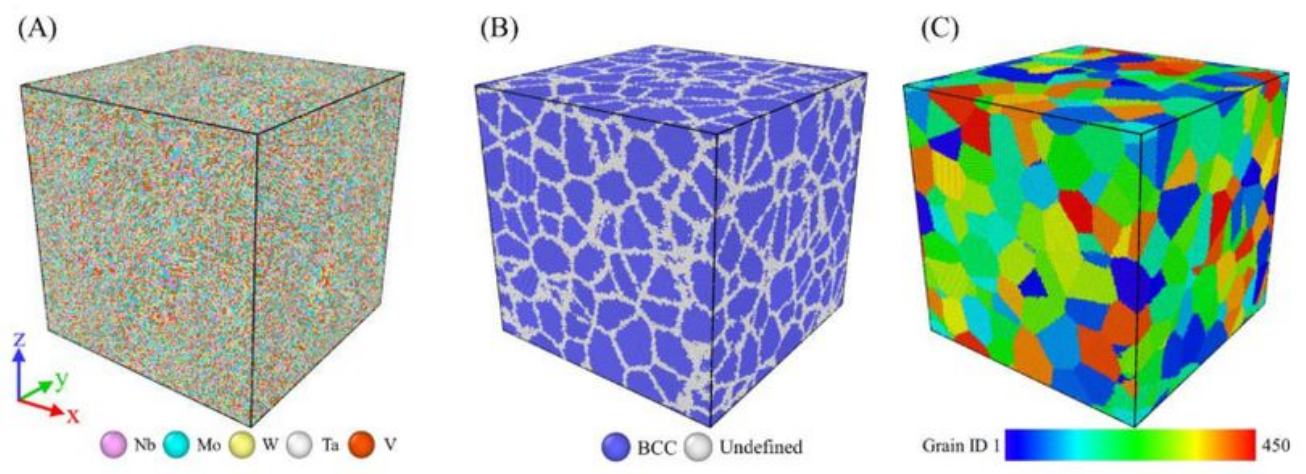

\section{Figure 1}

The polycrystalline Nb20.6Mo21.7Ta15.6W21.1V21.0 RHEA model with the average grain size about 5.2 $\mathrm{nm}$ for the heating process. The system size is about $40.7,40.7$, and $40.7 \mathrm{~nm}$ in the $\mathrm{x}-\mathrm{y}-$, and $\mathrm{z}^{-}$ dimensions, respectively. Atoms are colored according to (a) the element type, (b) grain and grain boundary atoms identified by the common neighbor analysis (CAN), and (c) the grain identity number. The current study considers the RHEAs with the average sizes of 25.3, 20.1, 15.6, 10.0, and $5.2 \mathrm{~nm}$. 


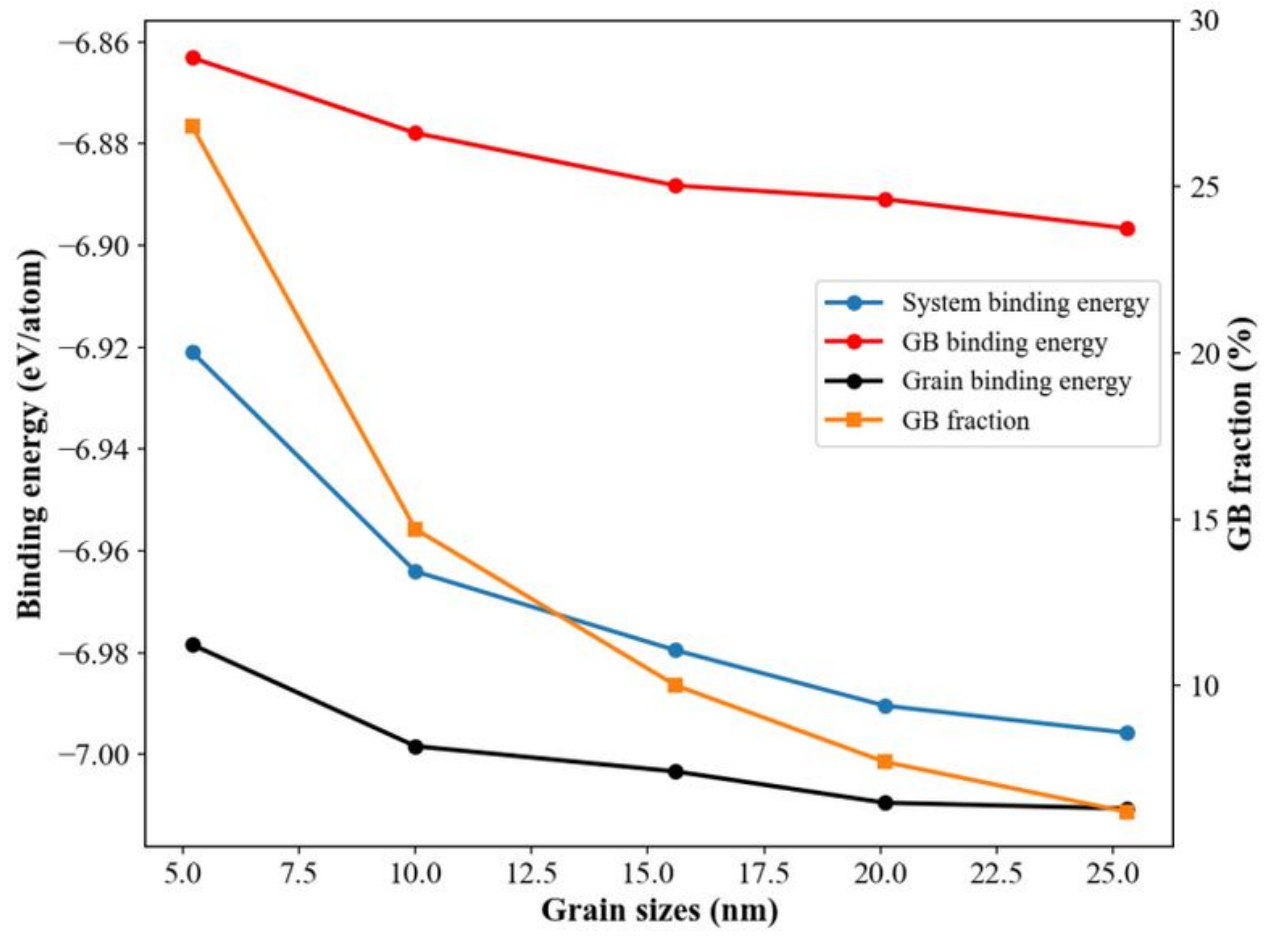

Figure 2

Profiles of GB fraction and the binding energies of grain, GB, and system for Nb20.6Mo21.7Ta15.6W21.1V21.0 RHEAs with the average grain size from 5.2 to $25.3 \mathrm{~nm}$.

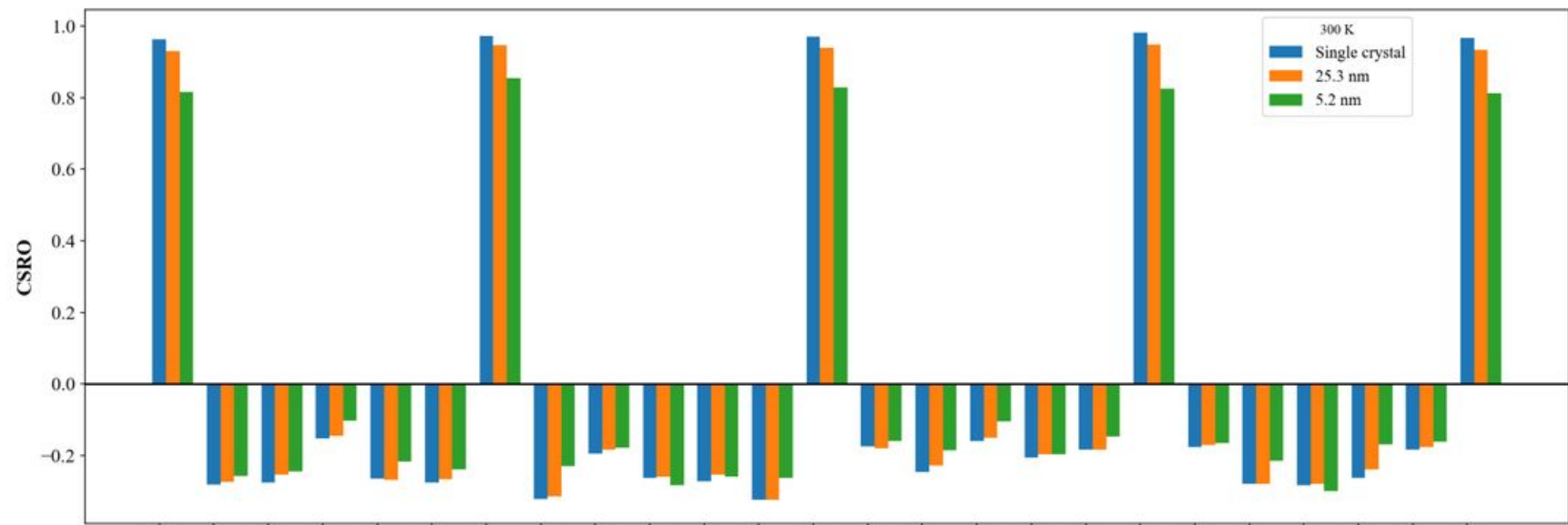

Nb-Nb Nb-Mo Nb-W Nb-Ta Nb-V Mo-Nb Mo-Mo Mo-W Mo-Ta Mo-V W-Nb W-Mo w-W w-Ta w-V Ta-Nb Ta-Mo Ta-W Ta-Ta Ta-V V-Nb V-Mo V-W V-Ta V-V 


\section{Figure 3}

The Nb20.6Mo21.7Ta15.6W21.1V21.0 RHEA CSRO distributions for (a) single crystal, (b) $25.3 \mathrm{~nm}$, and (c) $5.2 \mathrm{~nm}$ at $300 \mathrm{~K}$.

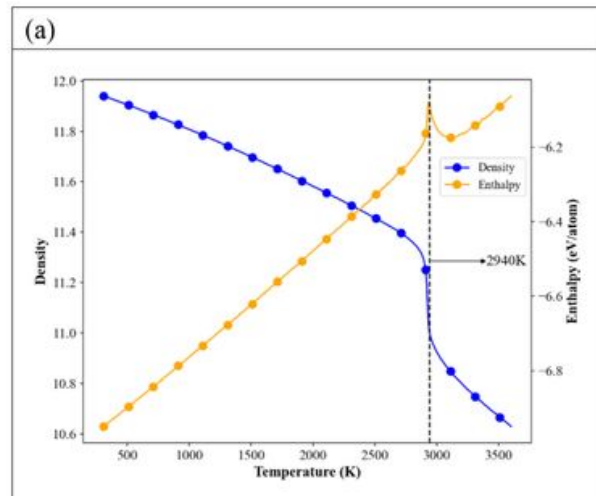

(b)

(c)
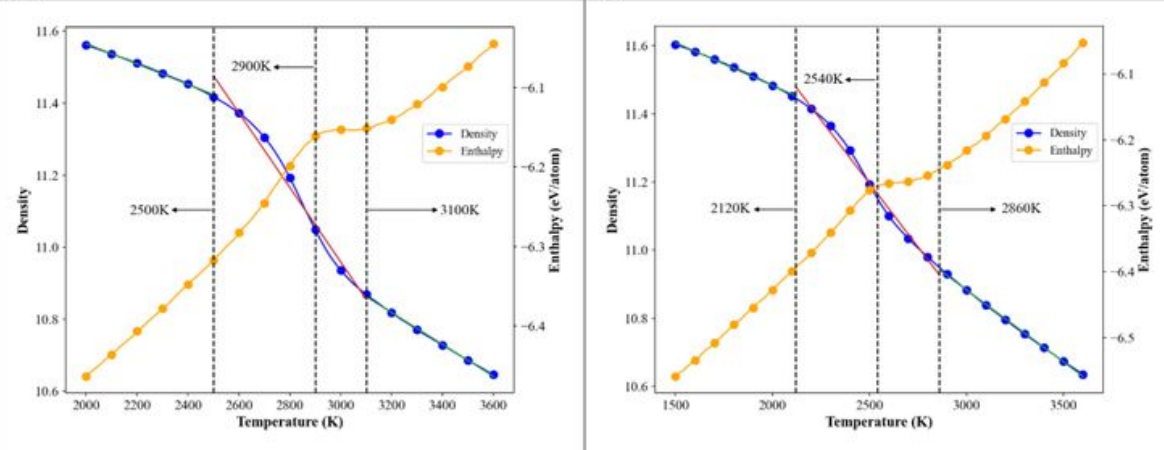

Figure 4

Density and enthalpy profiles of Nb20.6Mo21.7Ta15.6W21.1V21.0 RHEAs during the heating process for (a) single crystal, (b) $25.3 \mathrm{~nm}$, and (c) $5.2 \mathrm{~nm}$. The melting points of single crystal, $25.3 \mathrm{~nm}$, and $5.2 \mathrm{~nm}$ are 2940,2900 , and $2540 \mathrm{~K}$ as indicated by the dashed lines. The temperatures at discontinuities of density profiles of two polycrystalline RHEAs are also indicated by the dashed lines. 


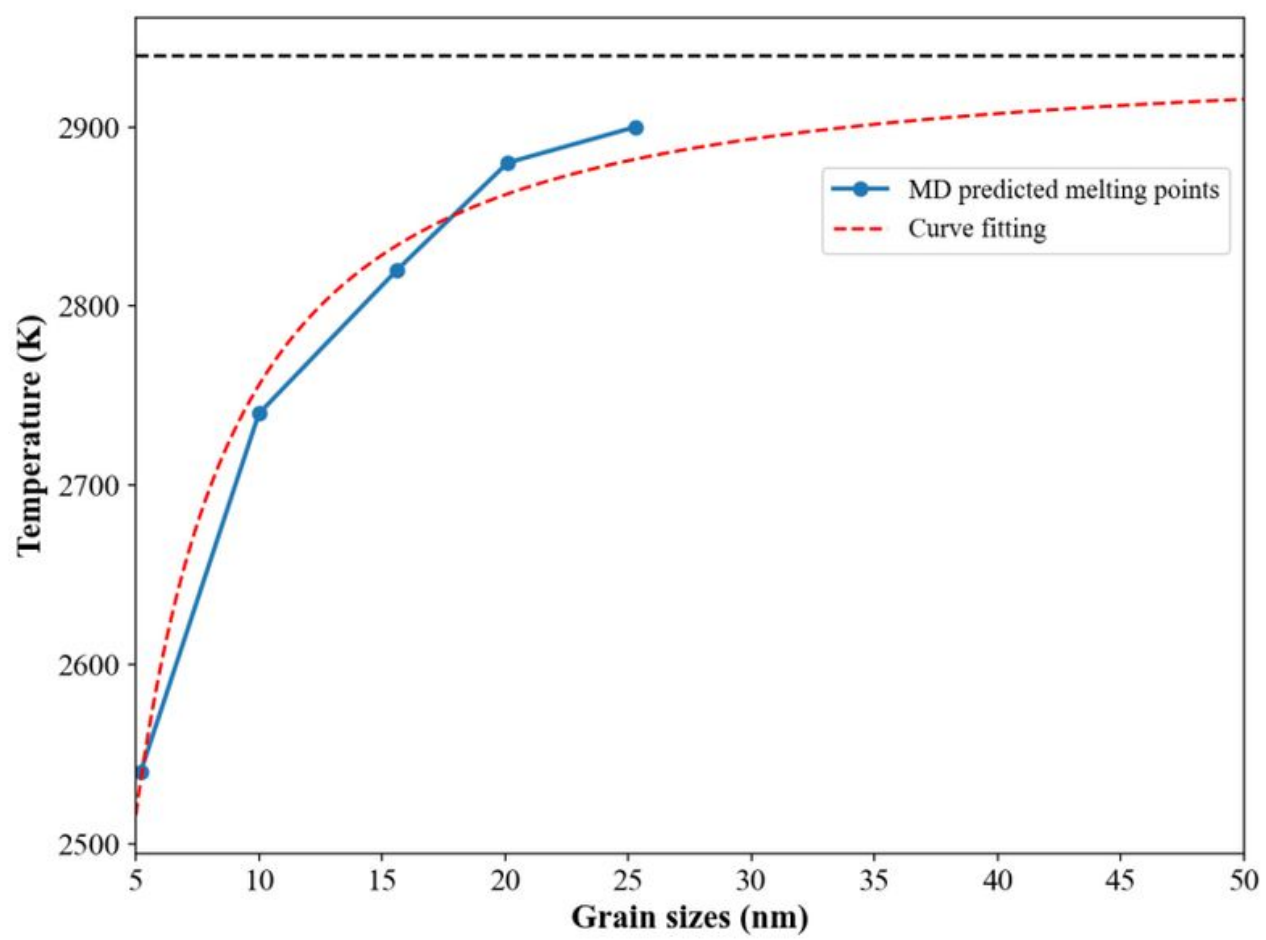

Figure 5

Profile of MD predicted melting points for polycrystalline Nb20.6Mo21.7Ta15.6W21.1V21.0 RHEAs with the average grain sizes from 5.2 to $25.3 \mathrm{~nm}$. The curve fitting profile using Eq. (2) is also provided. The horizontal dashed line stands for the melting point ( $2940 \mathrm{~K})$ of the single crystal Nb20.6Mo21.7Ta15.6W21.1V21.0 RHEA. 


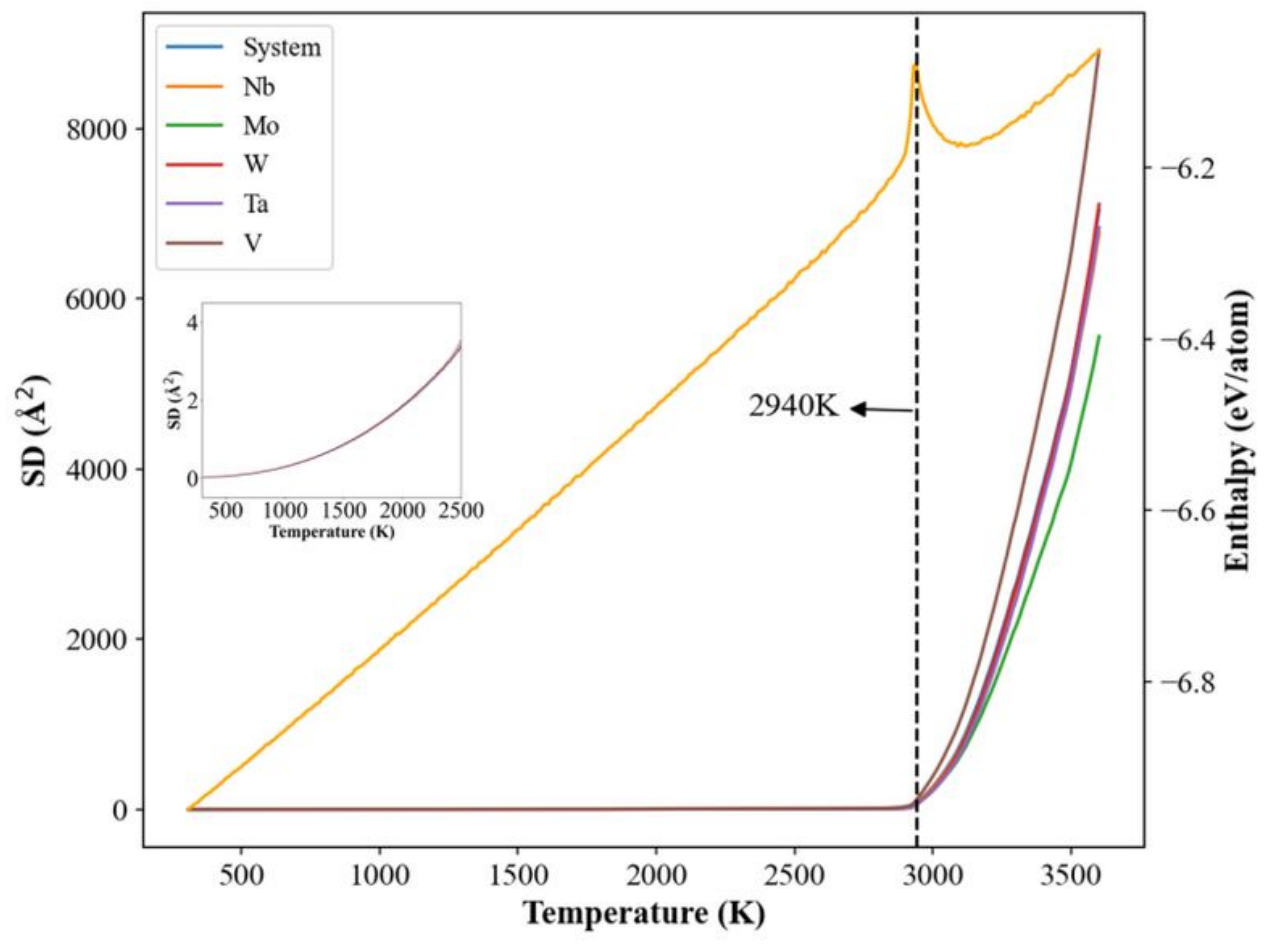

Figure 6

The square displacement (SD) and enthalpy profiles of system, $\mathrm{Nb}, \mathrm{Mo}, \mathrm{W}, \mathrm{Ta}$, and $\mathrm{V}$ during the heating process for the single crystal Nb20.6Mo21.7Ta15.6W21.1V21.0 RHEA. The insert shows SD profiles at temperatures lower than the melting point of $2940 \mathrm{~K}$. 


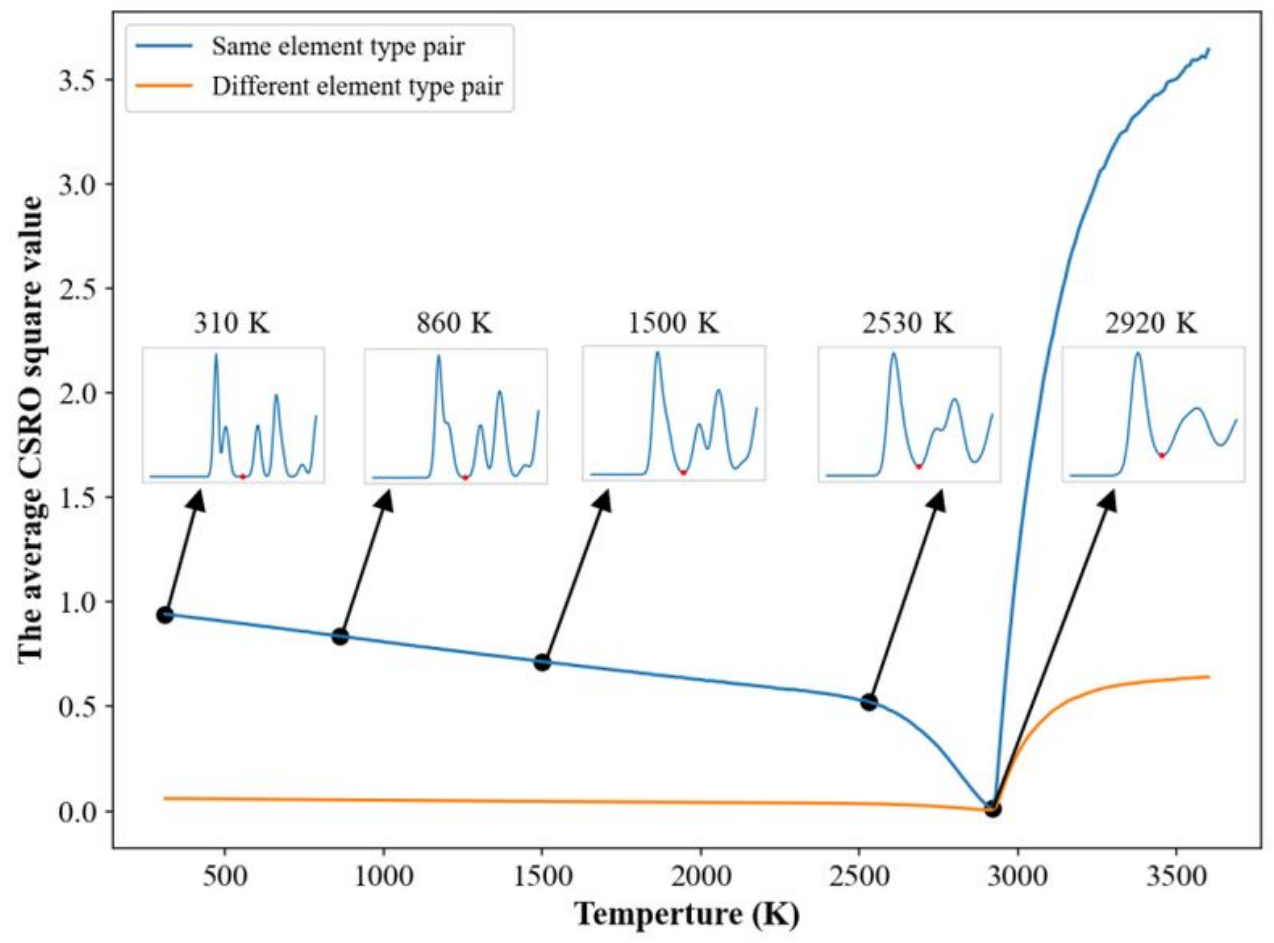

Figure 7

Average CSRO square profiles of the same and different element type pairs for the single crystal $\mathrm{Nb20.6Mo21.7Ta15.6W21.1V21.0} \mathrm{RHEA.} \mathrm{The} \mathrm{insets} \mathrm{show} \mathrm{the} \mathrm{RDF} \mathrm{profiles} \mathrm{at} \mathrm{different} \mathrm{temperatures}$ lower than the melting point of $2940 \mathrm{~K}$. 
(a)

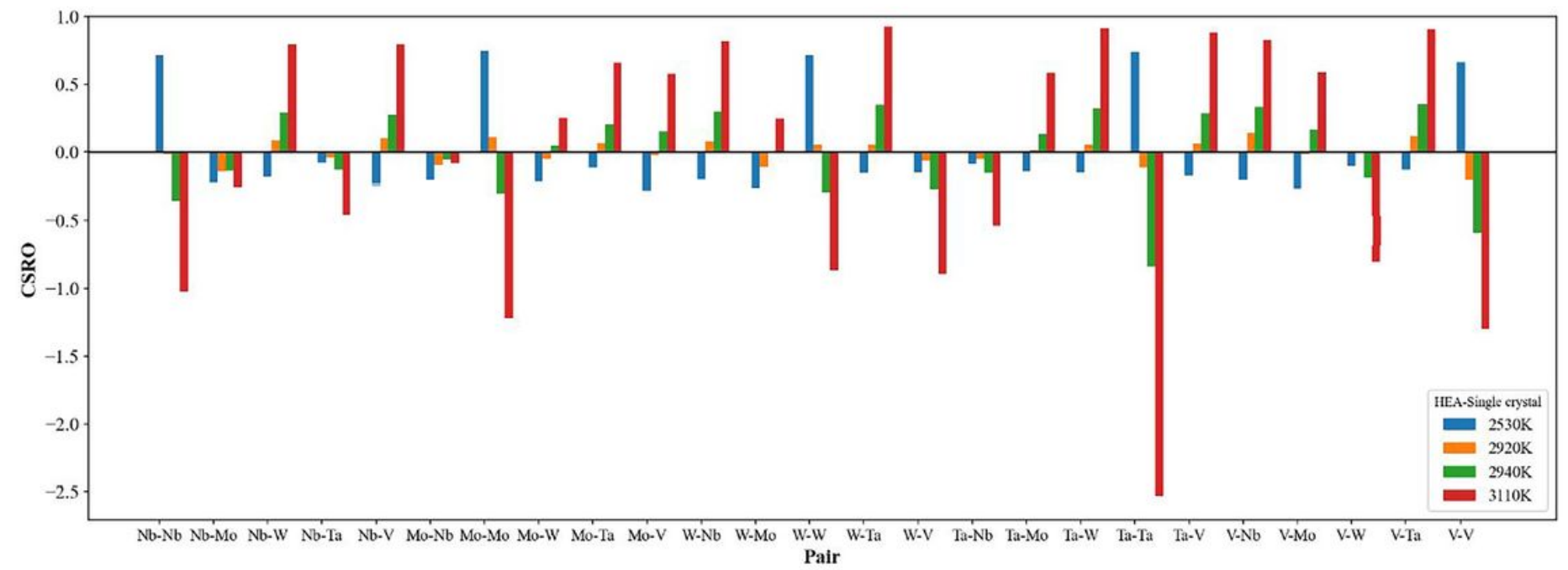

(b)

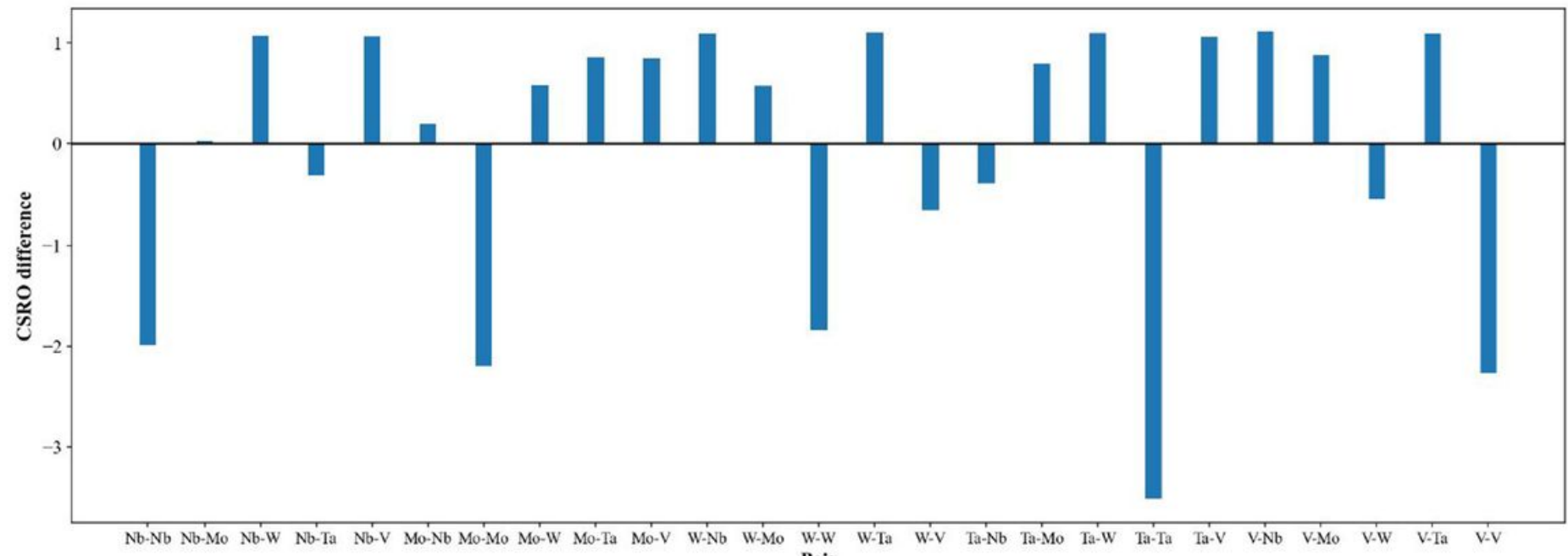

Figure 8

(a)The CSRO distributions for single crystal at four characteristic temperatures, 2530, 2920 (minimum of average CSRO square), 2940 (melting point), and $3110 \mathrm{~K}$. (b) the differences of CSRO values of all pairs between $300 \mathrm{~K}$ and $3110 \mathrm{~K}$. 

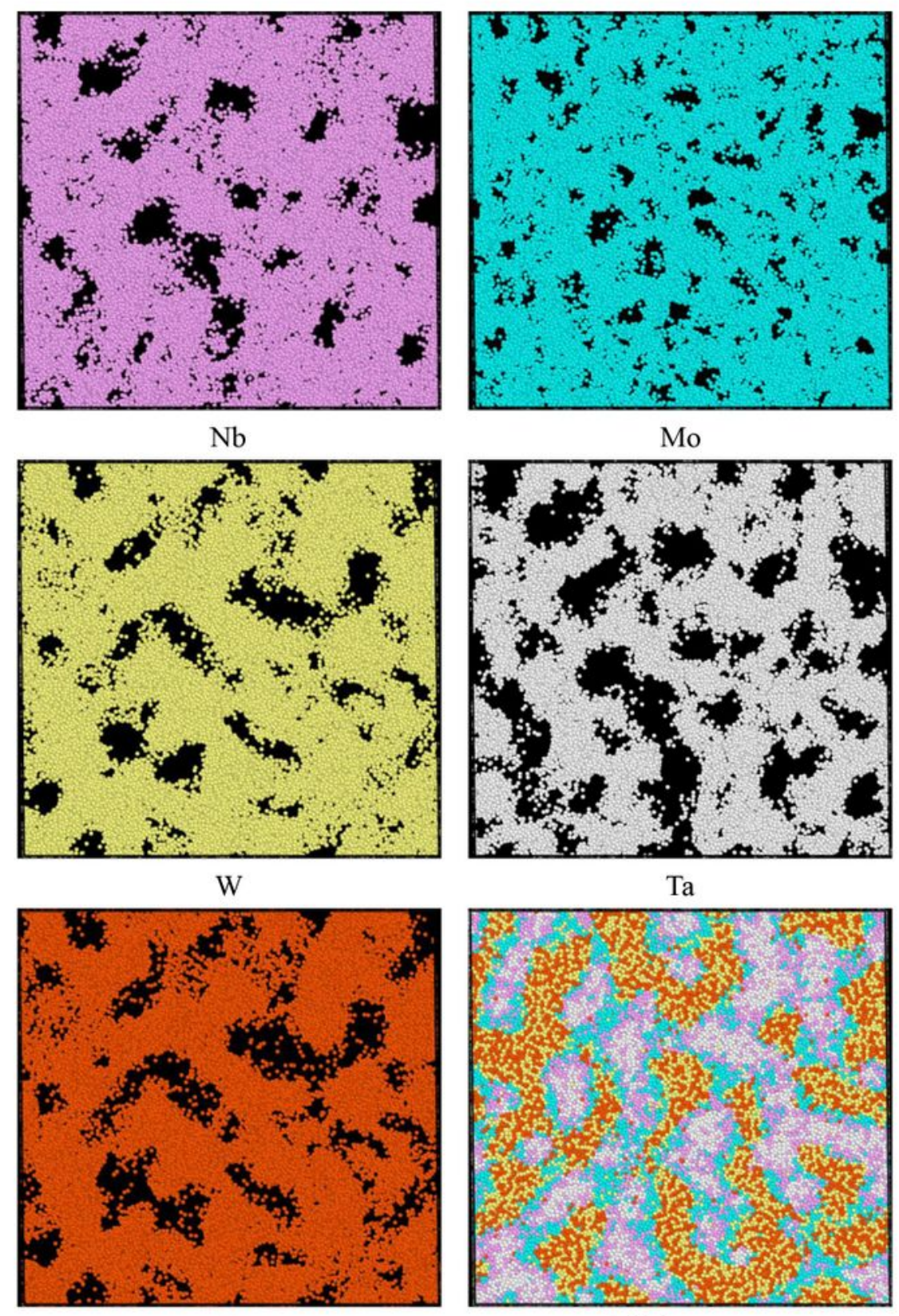

All elements

Figure 9

The distributions of $\mathrm{Nb}, \mathrm{Mo}, \mathrm{Ta}, \mathrm{W}, \mathrm{V}$, and all elements within the single crystal $\mathrm{Nb20.6Mo21.7Ta15.6W21.1V21.0} \mathrm{RHEA} \mathrm{at} \mathrm{3110} \mathrm{K.}$ 


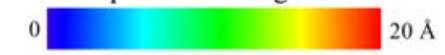

(a)

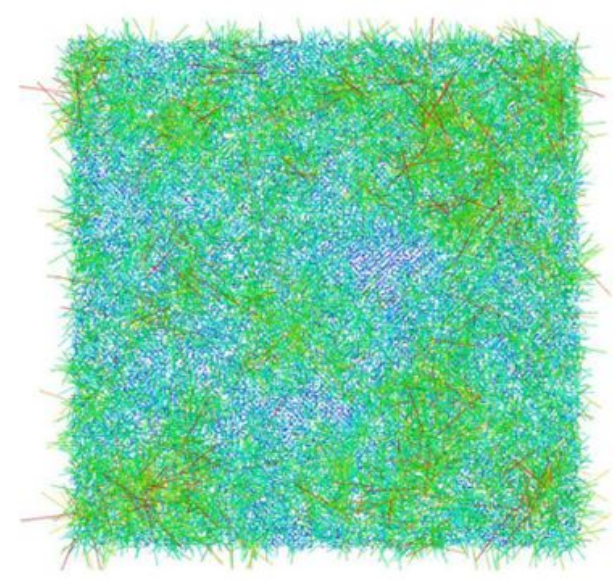

(b)

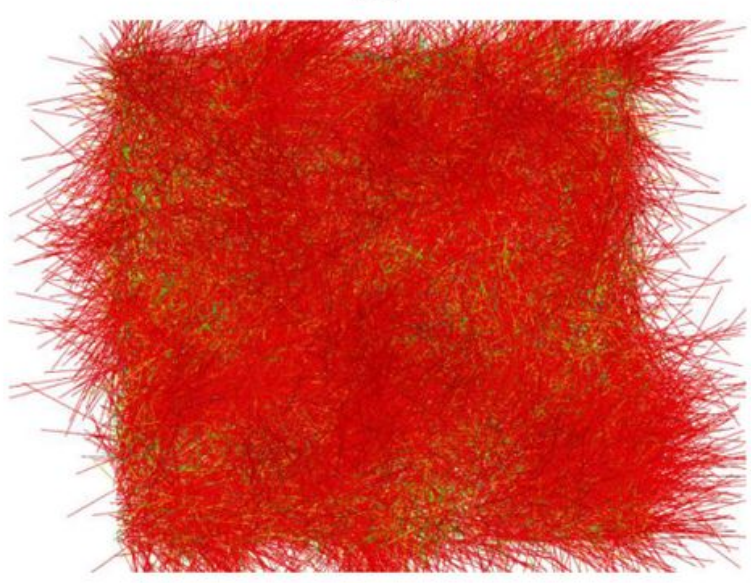

\section{Figure 10}

The atomic displacement vectors of the single crystal Nb20.6Mo21.7Ta15.6W21.1V21.0 RHEA at (a) the melting point of $2940 \mathrm{~K}$ and (b) $3110 \mathrm{~K}$. The atom positions at $300 \mathrm{~K}$ were used as the reference positions for calculating the atomic displacement vectors. 
(a)

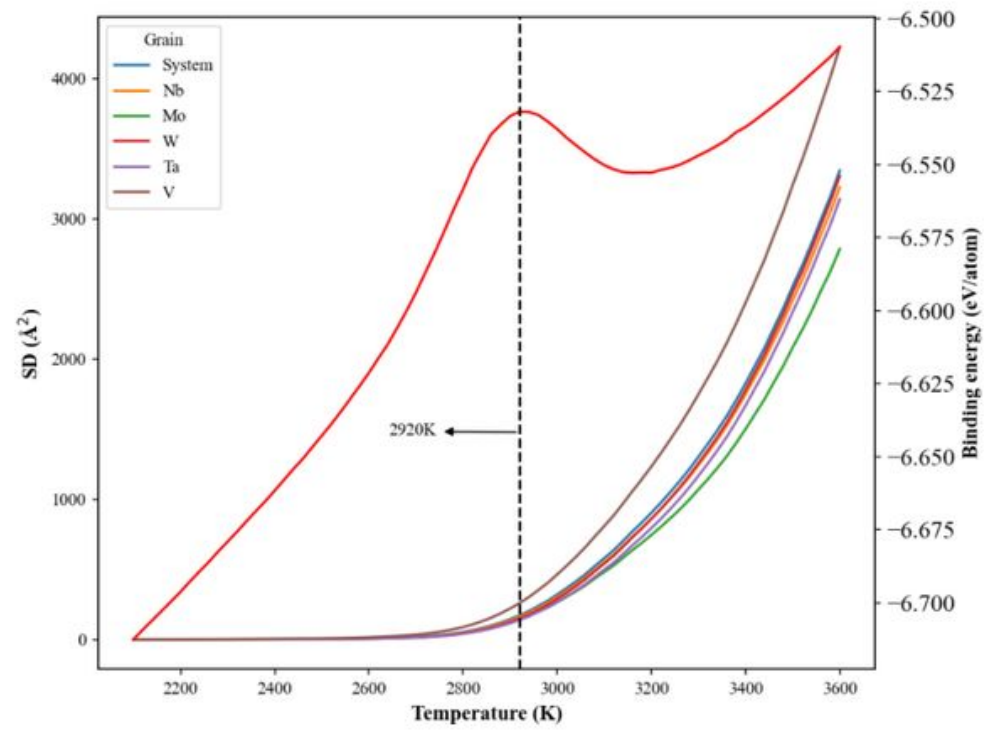

(b)

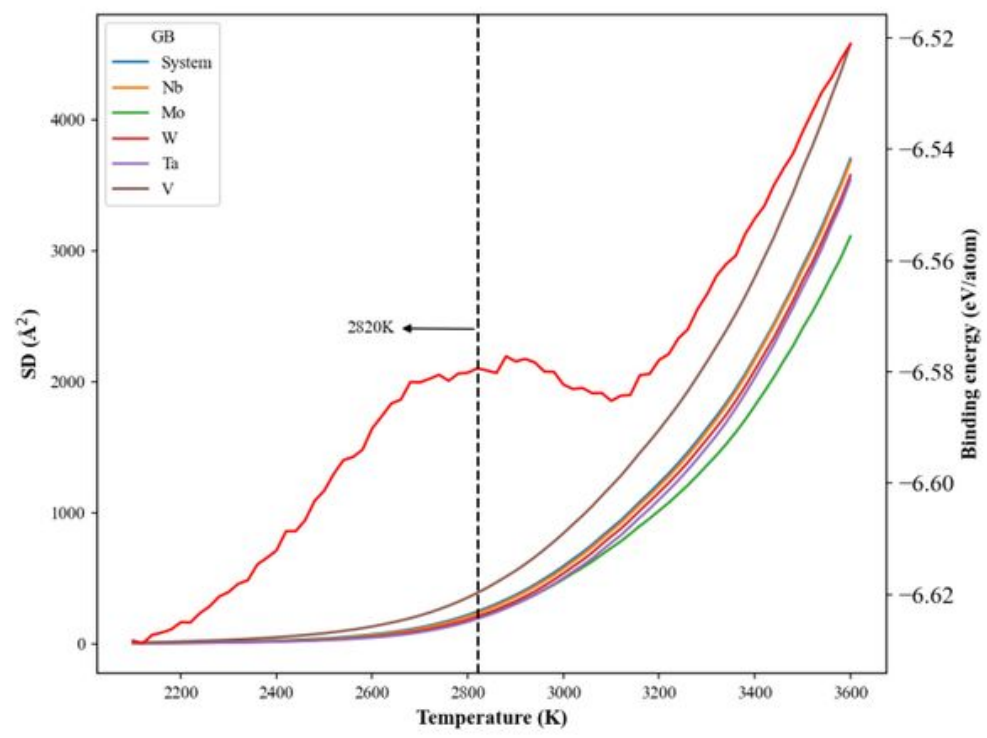

Figure 11

The binding energy and square displacement (SD) profiles of system, Nb, Mo, W, Ta, and $\mathrm{V}$ of (a) the grain atoms and (b) the GB atoms for the case with the average grain size of $25.3 \mathrm{~nm}$ during the heating process. 


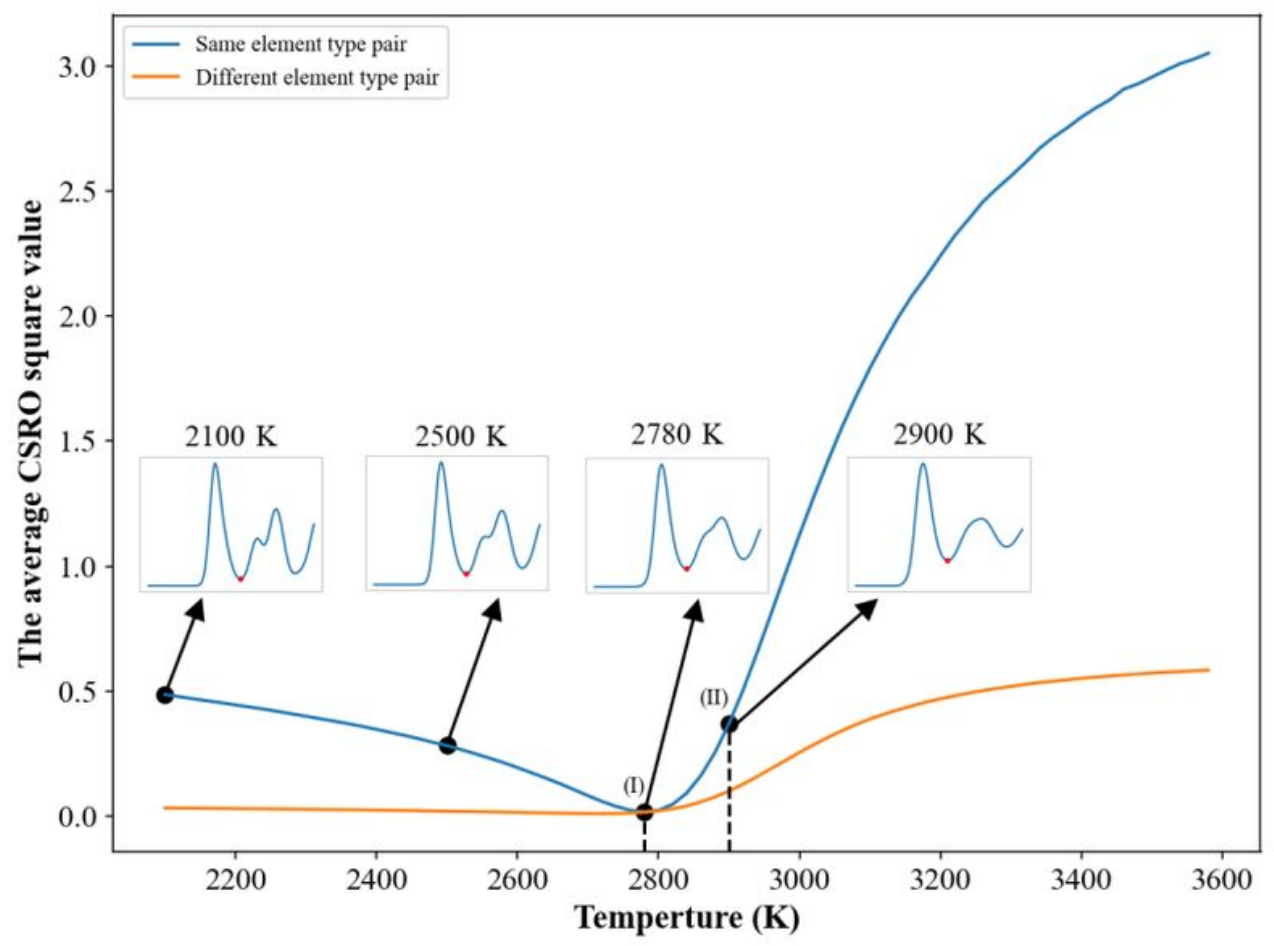

Figure 12

Average CSRO square profiles of the same and different element type pairs for the

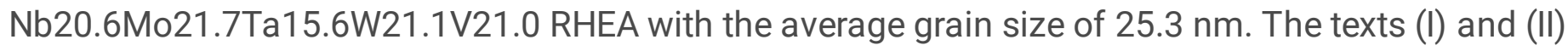
indicate the lowest value of average CSRO square of the same element pair at $2780 \mathrm{~K}$ and the melting point at $2900 \mathrm{~K}$. 


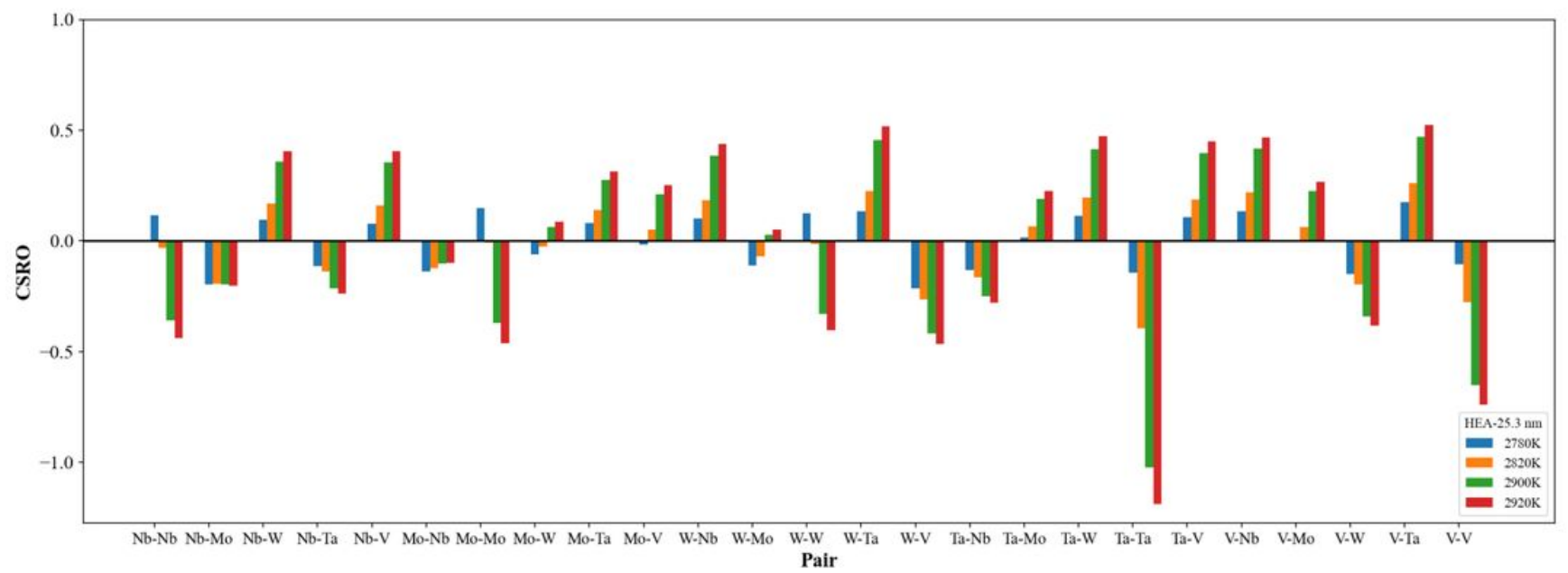

Figure 13

The CSRO distributions for the Nb20.6Mo21.7Ta15.6W21.1V21.0 RHEA with the average grain size of $25.3 \mathrm{~nm}$ at four characteristic temperatures, 2780 (minimum of average CSRO square), 2820 (pre-melting temperature), 2900 (melting point), and 2920 (binding energy peak of grain atom) K. 


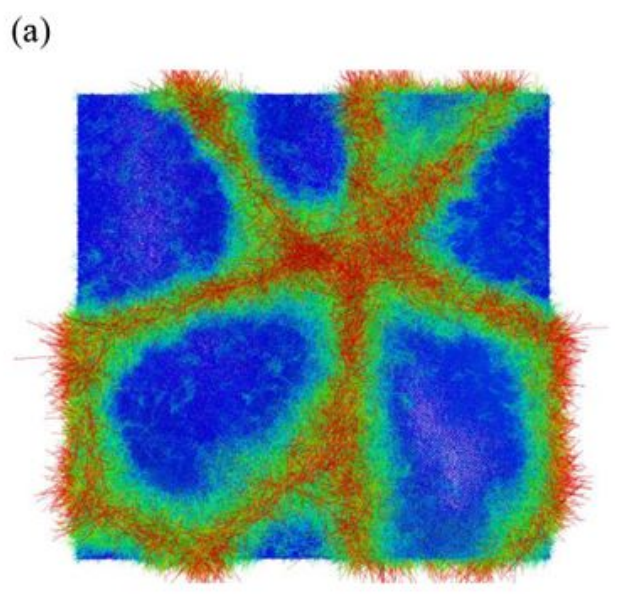

(b)

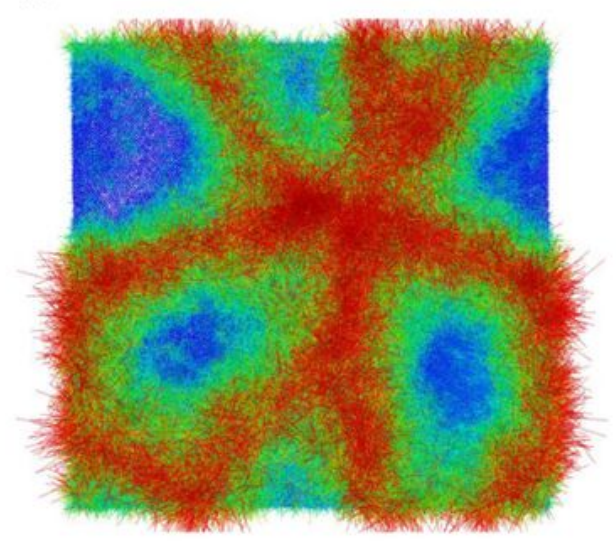

(c)

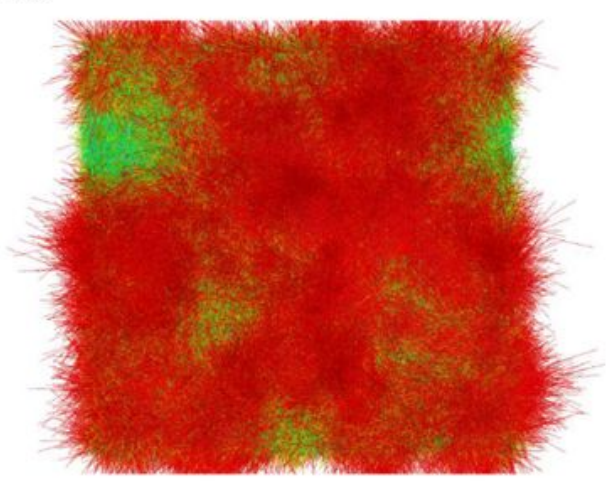

\section{Figure 14}

The atomic displacement vectors of $25.3 \mathrm{~nm}$ at (a) $2820 \mathrm{~K}$, (b) $2920 \mathrm{~K}$, and (c) $3100 \mathrm{~K}$, respectively. The atom positions at $300 \mathrm{~K}$ were used as the reference positons for the displacement vectors. 
(a)

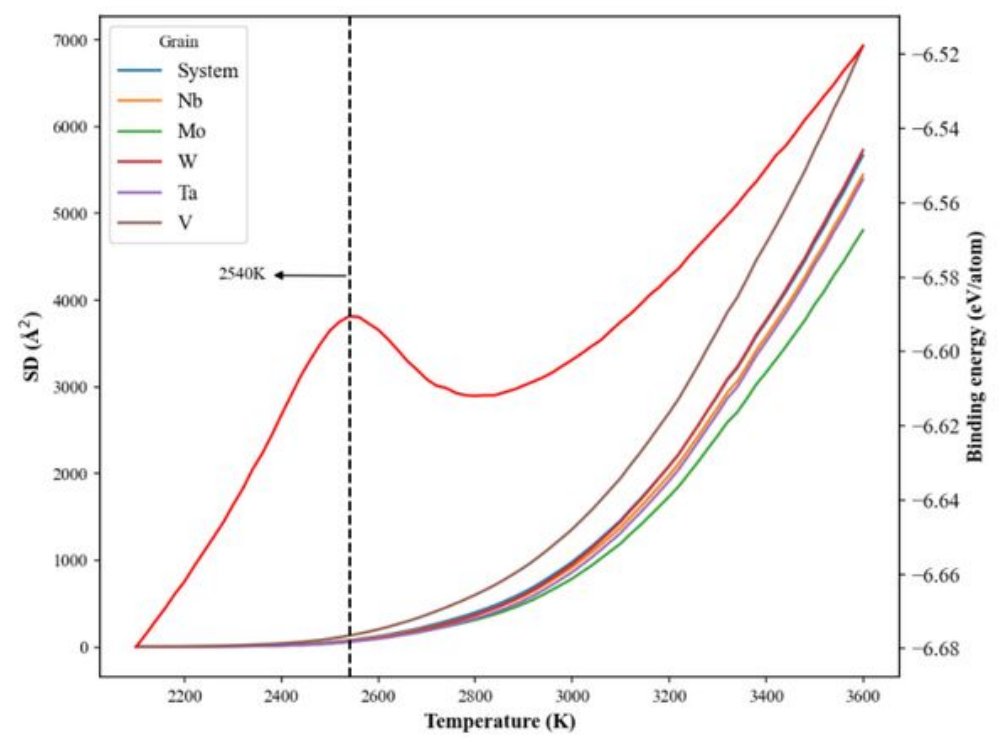

(b)

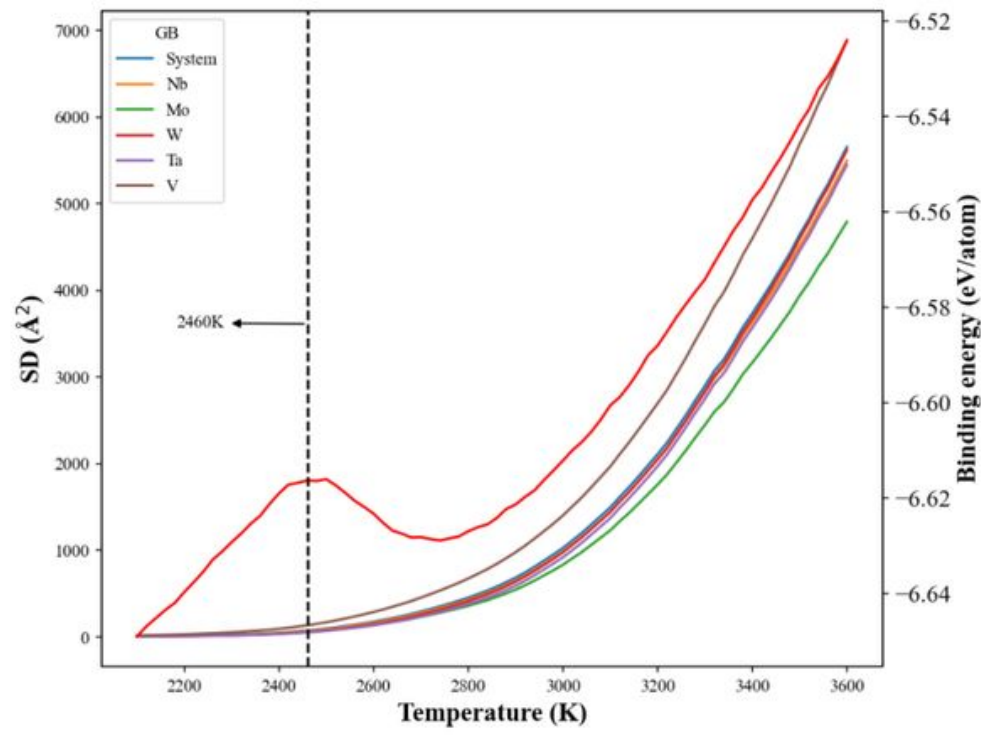

Figure 15

The binding energy and square displacement (SD) profiles of system, Nb, Mo, W, Ta, and $\mathrm{V}$ of (a) the grain atoms and (b) the GB atoms for the case with the average grain size of $5.2 \mathrm{~nm}$ during the heating process. 


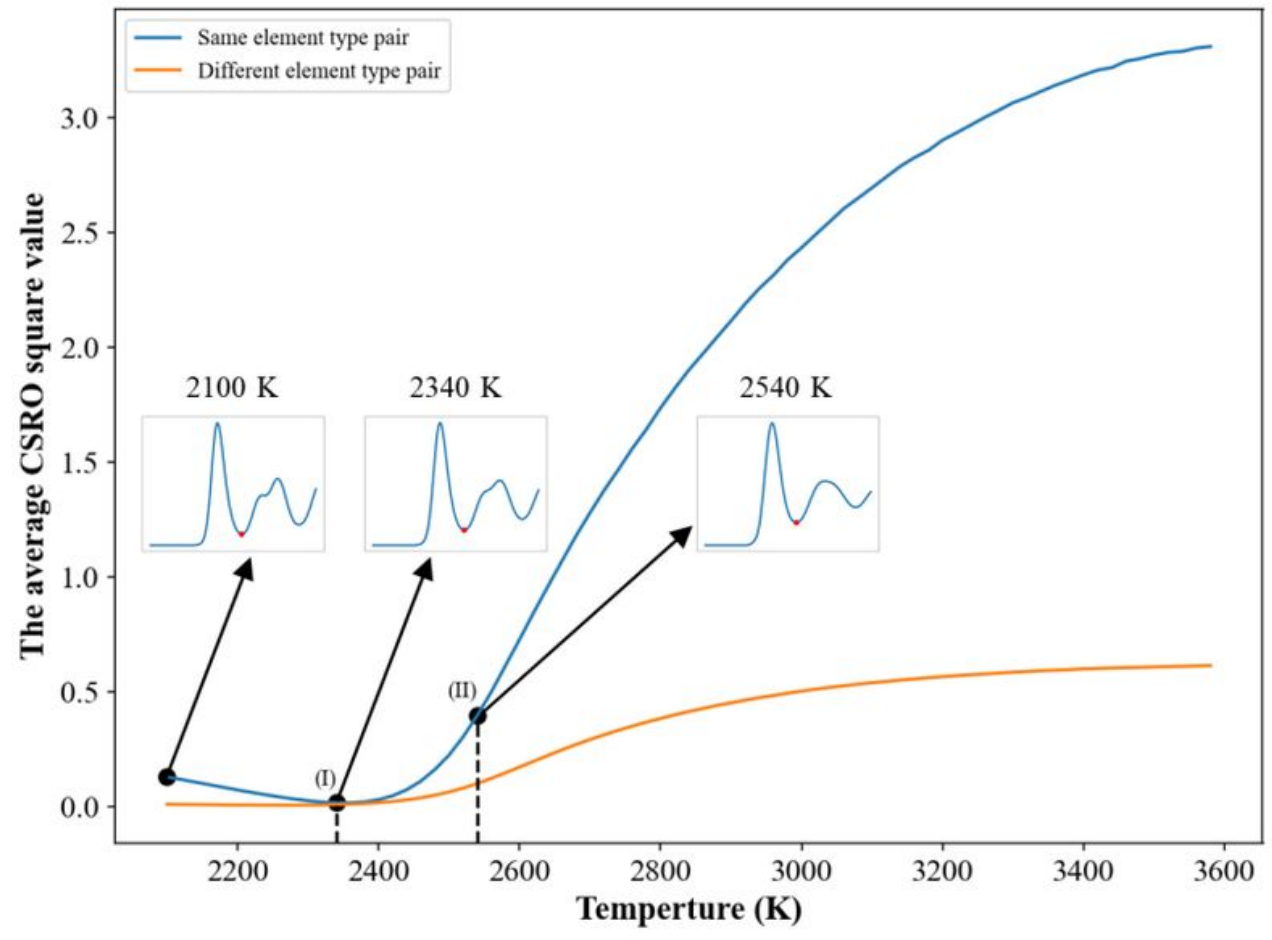

Figure 16

Average CSRO square profiles of the same and different element type pairs for the

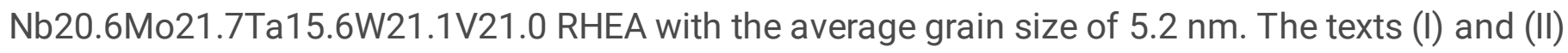
indicate the minimum of average CSRO square of the same element pair at $2340 \mathrm{~K}$ and the melting point at $2540 \mathrm{~K}$. 


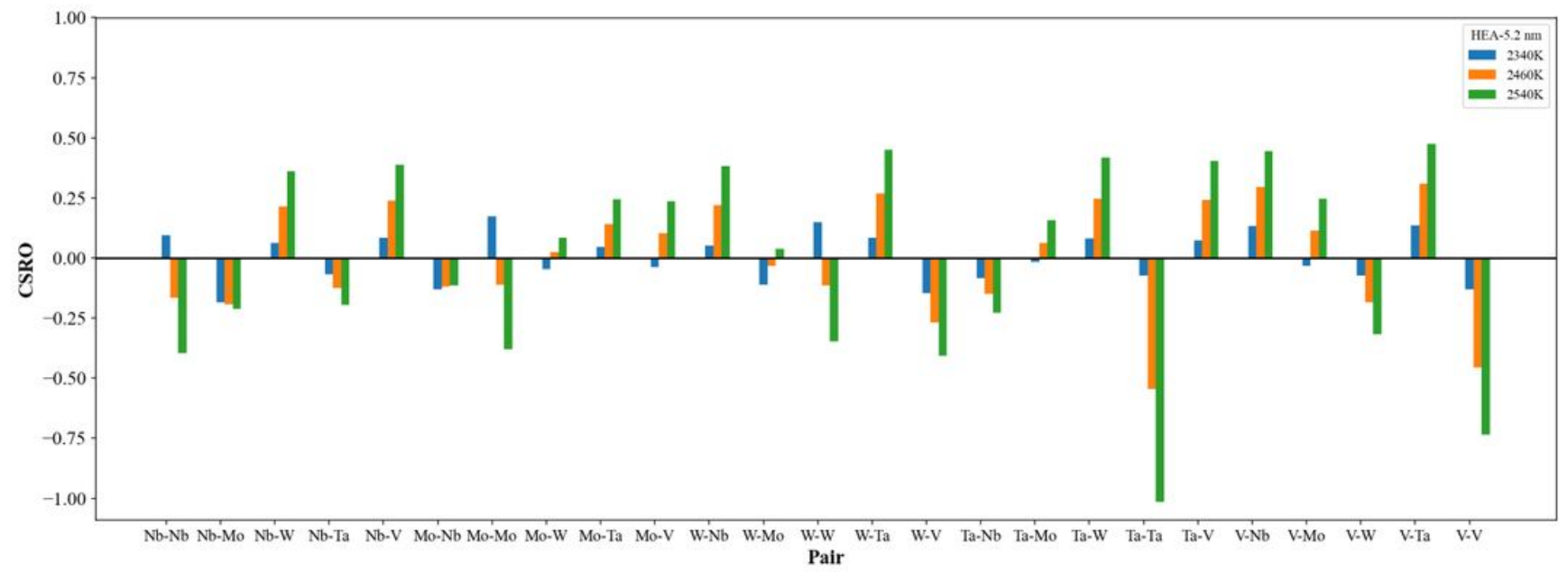

Figure 17

The CSRO distributions for the Nb20.6Mo21.7Ta15.6W21.1V21.0 RHEA with the average grain size of 5.2 $\mathrm{nm}$ at 2340 (minimum of average CSRO square), 2460 (pre-melting temperature), and 2540 (melting point and the binding energy peak of grain atom) $\mathrm{K}$. 
(a)

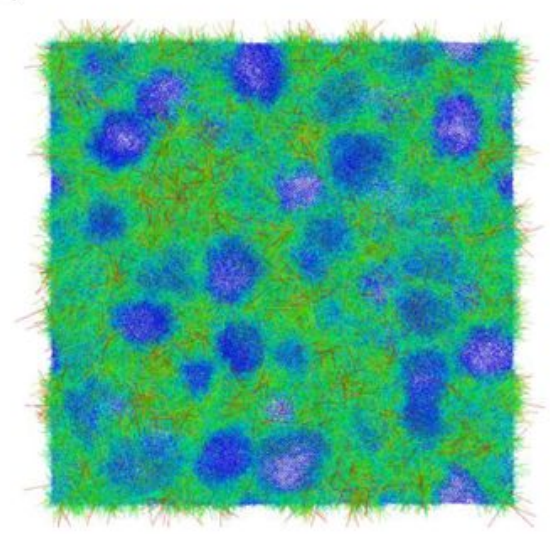

(b)

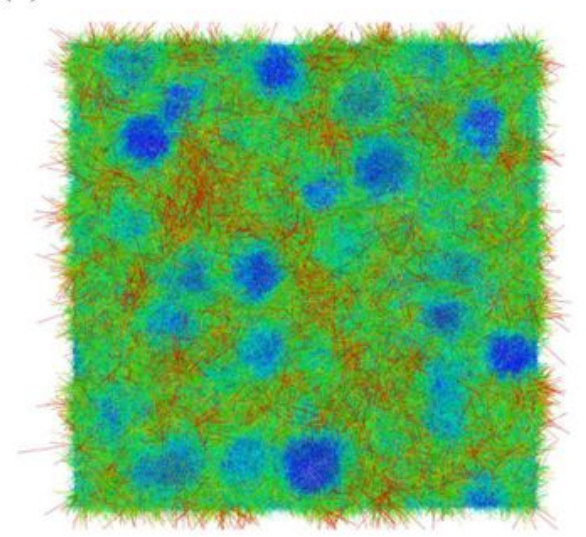

(c)

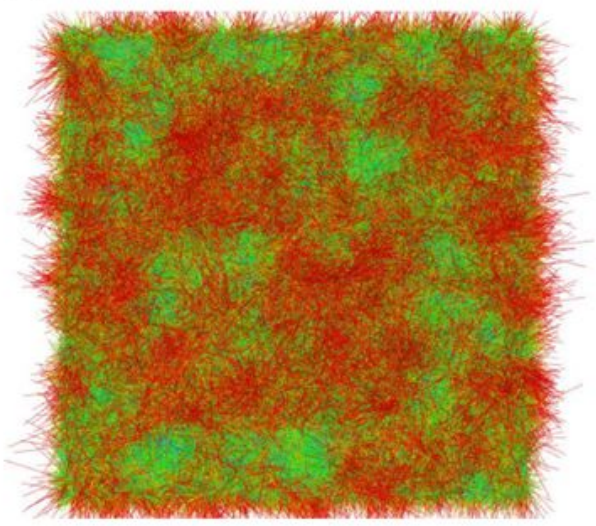

\section{Figure 18}

The atomic displacement vectors of the case with the grain size of $5.2 \mathrm{~nm}$ at (a) $2460 \mathrm{~K}$ (pre-melting temperature), (b) $2540 \mathrm{~K}$ (melting point and the binding energy peak of grain atom), and (c) $2700 \mathrm{~K}$, respectively. The atom positions at $300 \mathrm{~K}$ were used as the reference positons for the displacement vectors. 


\section{Supplementary Files}

This is a list of supplementary files associated with this preprint. Click to download.

- table.pdf

- Supplementary.pdf 